\title{
FUNCTIONAL CELL PHENOTYPE INDUCTION WITH TGF- $\beta 1$ AND COLLAGEN-POLYURETHANE SCAFFOLD FOR ANNULUS FIBROSUS RUPTURE REPAIR
}

\author{
J. Du ${ }^{1}$, R.G. Long ${ }^{1,2,7}$, T. Nakai ${ }^{3,7}$, D. Sakai ${ }^{3,7}$, L.M. Benneker ${ }^{4,7}$, G. Zhou ${ }^{5}$, B. Li ${ }^{6}$, D. Eglin ${ }^{1,7}$, J.C. Iatridis ${ }^{2,7}$, \\ M. Alini ${ }^{1,7}$, S. Grad ${ }^{1,7}$ and Z. Li $i^{1,7, *}$ \\ ${ }^{1}$ AO Research Institute Davos, Davos, Switzerland \\ ${ }^{2}$ Icahn School of Medicine at Mount Sinai, New York, USA \\ ${ }^{3}$ Tokai University School of Medicine, Isehara, Japan \\ ${ }^{4}$ Inselspital, University of Bern, Bern, Switzerland \\ ${ }^{5}$ Shenzhen Key Laboratory of Anti-Aging and Regenerative Medicine, Department of Medical Cell \\ Biology and Genetics, Health Sciences Centre, Shenzhen University, Shenzhen, China \\ ${ }^{6}$ Orthopaedic Institute, Medical College, Soochow University, Suzhou, Jiangsu, China \\ ${ }^{7}$ Collaborative Research Program Annulus Fibrosus Repair, AO Foundation, Davos, Switzerland
}

\begin{abstract}
Appropriate cell sources, bioactive factors and biomaterials for generation of functional and integrated annulus fibrosus (AF) tissue analogues are still an unmet need. In the present study, the AF cell markers, collagen type I, cluster of differentiation 146 (CD146), mohawk (MKX) and smooth muscle protein $22 \alpha$ (SM22 $\alpha$ ) were found to be suitable indicators of functional AF cell induction. In vitro 2D culture of human AF cells showed that transforming growth factor $\beta 1$ (TGF- $\beta 1$ ) upregulated the expression of the functional AF markers and increased cell contractility, indicating that TGF- $\beta 1$-pre-treated AF cells were an appropriate cell source for AF tissue regeneration. Furthermore, a tissue engineered construct, composed of polyurethane (PU) scaffold with a TGF- 31 -supplemented collagen type I hydrogel and human AF cells, was evaluated with in vitro 3D culture and ex vivo preclinical bioreactor-loaded organ culture models. The collagen type I hydrogel helped maintaining the AF functional phenotype. TGF- $\beta 1$ supplement within the collagen I hydrogel further promoted cell proliferation and matrix production of AF cells within in vitro 3D culture. In the ex vivo IVD organ culture model with physiologically relevant mechanical loading, TGF- $\beta 1$ supplement in the transplanted constructs induced the functional AF cell phenotype and enhanced collagen matrix synthesis. In conclusion, TGF- $\beta 1$ containing collagen-PU constructs could induce the functional cell phenotype of human AF cells in vitro and in situ. This combined cellular, biomaterial and bioactive agent therapy has a great potential for AF tissue regeneration and rupture repair.
\end{abstract}

Keywords: Annulus fibrosus, annular rupture repair, tissue engineering, transforming growth factor $\beta 1$, polyurethane scaffold, collagen type I hydrogel.

*Address for correspondence: Zhen Li, PhD, AO Research Institute Davos, Clavadelerstrasse 8, 7270, Davos Platz, Switzerland.

Telephone number: +41 814142325 Email: zhen.li@aofoundation.org

Copyright policy: This article is distributed in accordance with Creative Commons Attribution Licence (http://creativecommons.org/licenses/by-sa/4.0/).

\section{List of Abbreviations}

ACAN ADAMTS5 aggrecan

a disintegrin and metalloproteinase with thrombospondin type I motifs, member 5 annulus fibrosus $\alpha \mathrm{MEM}$

APC

BSA

CCL4

CD146 COL1A2 alpha minimum essential medium allophycocyanin bovine serum albumin hemokine (C-C motif) ligands 4 cluster of differentiation 146 collagen type I alpha 2 


\begin{tabular}{|c|c|}
\hline COL1A1 & collagen type I alpha 1 \\
\hline COL2A1 & collagen type II alpha 1 \\
\hline DAPI & $\begin{array}{l}\text { 4',6-diamidino-2- } \\
\text { phenylindole }\end{array}$ \\
\hline DMEM & $\begin{array}{l}\text { Dulbecco's modified Eagle } \\
\text { medium }\end{array}$ \\
\hline ECM & extracellular matrix \\
\hline EDTA & $\begin{array}{l}\text { ethylenediaminetetraacetic } \\
\text { acid }\end{array}$ \\
\hline ELN & elastin \\
\hline EP & endplate \\
\hline ERK & $\begin{array}{l}\text { extracellular signal- } \\
\text { regulated kinases }\end{array}$ \\
\hline FACS & $\begin{array}{l}\text { fluorescence-activated cell } \\
\text { sorting }\end{array}$ \\
\hline FAM & carboxyfluorescein \\
\hline FBS & foetal bovine serum \\
\hline FCS & foetal calf serum \\
\hline GAG & glycosaminoglycan \\
\hline HMDI & $\begin{array}{l}\text { 1,6-hexamethylene } \\
\text { diisocyanate }\end{array}$ \\
\hline iAF & inner $\mathrm{AF}$ tissue \\
\hline IVD & intervertebral disc \\
\hline ISO & 1,4,3,6-dianhydro-D-sorbitol \\
\hline LBP & low-back pain \\
\hline MMP3 & matrix metalloproteinase 3 \\
\hline MKX & mohawk homeobox \\
\hline MSCs & mesenchymal stem cells \\
\hline MRI & magnetic resonance imaging \\
\hline NEAA & non-essential amino acid \\
\hline NP & nucleus pulposus \\
\hline oAF & outer AF tissue \\
\hline PBS & phosphate-buffered saline \\
\hline PCL & poly( $\varepsilon$-caprolactone) \\
\hline PU & polyurethane \\
\hline PU-Col & $\begin{array}{l}\text { PU scaffold-collagen } \\
\text { hydrogel }\end{array}$ \\
\hline PU-Col-AFCs & $\begin{array}{l}\text { PU-Col with TGF- } \beta 1 \text { pre- } \\
\text { treated AF cells }\end{array}$ \\
\hline PU-Col-AFCs-TGF $\beta$ & $\begin{array}{l}\text { PU-Col-AFCs and } 5 \text { ng } \\
\text { TGF- } \beta 1\end{array}$ \\
\hline qRT-PCR & $\begin{array}{l}\text { quantitative real-time } \\
\text { polymerase chain reaction }\end{array}$ \\
\hline RPLP0 & $\begin{array}{l}\text { ribosomal protein lateral } \\
\text { stalk subunit P0 }\end{array}$ \\
\hline SCX & scleraxis \\
\hline SM22 $\alpha$ & $\begin{array}{l}\text { smooth muscle protein } \\
\text { 22-alpha }\end{array}$ \\
\hline TAMRA & tetramethylrhodamine \\
\hline TGF- $\beta 1$ & $\begin{array}{l}\text { transforming growth factor } \\
\beta 1\end{array}$ \\
\hline VCAN & versican \\
\hline
\end{tabular}

\section{Introduction}

LBP has become one of most common chronic health problems. Approximately $80 \%$ of the population has been affected by LBP at least once in their life, representing a high economic and social burden (Dionne et al., 2006; Hoy et al., 2012; Hoy et al., 2010). IVD degeneration and disc herniation are well-known as leading causes of specific LBP (Roberts et al., 2006). In IVD herniation, the NP protrudes out of the defective AF and irritates and compresses the spinal nerves, resulting in pain and dysfunction. Furthermore, the integrity of the IVD is destroyed, which leads to mechanical property loss (consequently, reduced disc height), inflammation and further disc degeneration (Goupille et al., 1998; Humphreys and Eck, 1999). Microdiscectomy/ sequestrectomy is the standard surgical treatment for patients with severe dysfunction or without satisfactory outcomes after conservative therapy. The acute symptoms are relieved by removing herniated tissue. However, AF defects remain unrepaired, which leads to a 10-30\% re-herniation rate resulting in recurrent pain and continuing disc degeneration (Ambrossi et al., 2009; Carragee et al., 2003; Smith et al., 2010). Aggressive discectomy with removal of all NP material reduces the risk of re-herniation but will lead to a post-discectomy syndrome with rapid disc degeneration and pain in nearly one third of the patients (Watters and McGirt, 2009).

Several attempts have been made at AF repair after discectomy, such as direct suture and conglutination with glue; however, outcomes have been unsatisfactory (Ahlgren et al., 2000; Bailey et al., 2013; Guterl et al., 2014; Heuer et al., 2008). The self-healing capacity of the AF tissue is confined due to its avascular nature. Additionally, with the IVD as a load-bearing tissue, the repair of the AF should not only restore its mechanical properties but also reproduce its biological integrity (Chu et al., 2018). Tissue engineering has been demonstrated to be a prospective approach for AF repair in the last few decades (Agnol et al., 2018; Borem et al., 2017; Frauchiger et al., 2018; Hussain et al., 2018; Pirvu et al., 2015). However, appropriate cell sources, growth factors and biomaterials for generation of functional and integrated AF tissue analogues are still unmet needs.

MSCs have been proposed as a suitable cell source for IVD regenerative therapies (Sakai and Grad, 2015). In an ovine lumbar disc degeneration model, injection of bone-marrow-derived MSCs into previously incised AF resulted in a significant improvement in histological, biochemical and MRI analyses (Freeman et al., 2016). Nevertheless, the fate of the implanted cells and their potential to differentiate into AF-like cells remain uncertain. In a previous study, MSCs were transplanted into AF defects of bovine caudal IVDs and cultured in an organ culture model under dynamic load for $14 \mathrm{~d}$, to investigate the phenotype of MSCs after transplantation and their paracrine effect on native disc cells (Pirvu et al., 2015). MSCs showed the ability to positively affect the phenotype of the host disc cells, as indicated by the up-regulation of anabolic genes and downregulation of catabolic genes. However, no effect was detected on new matrix formation at the AF defect site. This finding demonstrated that non-primed 
MSCs have limited capacity to differentiate into AF cells in situ. An effective cell population with repair ability is required to reconstruct an AF tissue with normal functions. AF cells possess the innate capacity to rebuild the biological properties of tissueengineered AF analogues (Iu et al., 2017; Yang et al., 2009). However, phenotypic markers of functional AF cells as a guideline for seed cell selection are still missing, except for collagen type I, which is the prominent ECM component in the AF. Recently, Nakai et al. (2016) have demonstrated that CD146 murine AF cells deposit more collagen type I-rich ECM as compared with CD146- cells, indicating that CD146 may be a marker of functional AF cells. The present study unravelled further molecular markers of healthy AF cells as compared with NP cells. Then, these markers were used as indicators of functional AF cell induction.

Several studies have shown that TGF- $\beta 1$ enhances ECM production and cell proliferation of human AF cells in both 2D and 3D in vitro cultures (Chou et al., 2016; Gruber et al., 2004). TGF- $\beta 1$ increases myofibroblast contractility in wound healing, which plays a pivotal role in physiological tissue remodelling (Tomasek et al., 2002). TGF- $\beta 1$ can also prevent degenerative processes and inhibit inflammatory responses in the dorsal root ganglion and prevent pain development in a rat IVD degeneration model (Zhang et al., 2017). Therefore, the effect of TGF- $\beta 1$ on the expression of the functional markers in human AF cells was investigated. In addition to $2 \mathrm{D}$ and $3 \mathrm{D}$ in vitro culture systems, TGF- $\beta 1$-treated AF cells were tested in a preclinical IVD organ culture model to reveal their repair effect in situ.

In addition to cell source and growth factor, a biomaterial with appropriate biological and biomechanical compatibility is crucial for successful regeneration of AF tissue in situ. PU scaffolds have been reported to have excellent biocompatibility, mechanical property and stability for AF tissue engineering (Agnol et al., 2018; Yeganegi et al., 2010). Whatley et al. (2011) developed a PU scaffold to mimic the native shape and structure of the IVD that exhibited elastic behaviour during compressive and shear testing and supported cell growth. Lee et al. (2005) and Li et al. (2009) have performed research on PU scaffolds with an interconnected pore structure for cartilage tissue engineering. Results showed that PU scaffolds have sufficient elasticity, resiliency and stiffness to endure in vitro mechanical loading. Hydrogels such as collagen, agarose, fibrin and alginate are widely used to encapsulate and deliver cells into scaffolds, preventing cell loss from scaffold and enhancing the retention of matrix molecules (Alini et al., 2003). Collagen type I, the main component of AF ECM, has been coated on to plastic, promoting AF cell proliferation and matrix production in vitro (Xiao et al., 2017). A crosslinked collagen I hydrogel was injected to repair AF rupture in a punctured rat-tail model. Results showed that collagen gel can preserve the integrity of the AF and NP after needle puncture, while delaying the degeneration of the IVD (Wang et al., 2017). Bowles et al. (2010) found that a collagen I hydrogel seeded with ovine AF cells display a capacity for selfassembly of aligned tissue-engineered AF through collagen gel contraction. Those studies indicated a good potential of collagen I hydrogel for AF cells proliferation and AF matrix synthesis. However, the specific phenotypes of the AF cells within these various biomaterials have not yet been reported.

The current study aimed to define the functional markers of healthy AF cells and assess the in vitro and ex vivo effect of a bioactive agent-biomaterial approach for functional AF cells priming and AF rupture repair. First, the markers of functional AF cells were defined; then, potential cell sources (AF cells) with growth factor (TGF- $\beta 1$ ) for functional phenotype induction were assessed; finally, those were combined with biomaterials. PU scaffolds with/ without collagen I hydrogel were assessed for their capacity to support and maintain the functional phenotype of AF cells in an in vitro 3D culture model and an ex vivo preclinical organ culture model. Cell proliferation, matrix production and gene expression were evaluated in vitro. Ex vivo tests were performed on bovine caudal IVDs with an organ culture system including a mechanical loading bioreactor. The morphology of regenerated tissue and the phenotype of implanted and native disc cells were analysed to assess the repair effect of constructs in an AF defect in situ.

\section{Materials and Methods}

\section{Fabrication of PU scaffold and PU membrane}

PU was synthesised using a one-step solution polycondensation as described previously (Gorna and Gogolewski, 2006). Briefly, the monomers and macromers used for the synthesis were HMDI (Sigma-Aldrich), hydroxyl-terminated PCL (SigmaAldrich), with an average molecular weight of $530 \mathrm{~g} / \mathrm{mol}$ and a functionality of 2, and ISO (SigmaAldrich). The reactants underwent a one-step polycondensation in solution in the presence of a catalyst. The HMDI : PCL : ISO molar ratio used was $1: 0.32: 0.64$. The PU obtained had intrinsic viscosity, weight average molecular weight and polydispersity of $1.3 \mathrm{dL} / \mathrm{g}, 500,000 \mathrm{~g} / \mathrm{mol}$ and 2.00, respectively.

Membranes were produced by casting the N,Ndimethylformamide solution of the synthesised PU into a flat-bottom glass Petri dish and allowing the solvent to evaporate under a chemical hood. The measured ultimate strength of the PU membrane was $53.0 \pm 2.0 \mathrm{MPa}$, the yield strength $4.9 \pm 1.4 \mathrm{MPa}$ and the elongation at break $593.8 \pm 57.7 \%$. The surface of the PU membrane did not present large porosity and was mostly smooth on the top and bottom (Pirvu et al., 2015).

Porous PU sponges with interconnected pore size diameter of $150-300 \mu \mathrm{m}$ were produced using 
a salt leaching-phase inverse fabrication extensively reported elsewhere (Boissard et al., 2009; Lee et al., 2005). Water-jet cutting was used to produce cylindrical scaffolds of $3 \mathrm{~mm}$ diameter, $4 \mathrm{~mm}$ thickness and scaffolds were sterilised by cold ethylene oxide and degassed for $5 \mathrm{~d}$ before use. The unconfined compressive stiffness of the prepared scaffolds was approximately $20 \mathrm{kPa}$ (Grad et al., 2003).

\section{Isolation and expansion of human AF cells}

Human IVD tissue was harvested with ethical approval (Cantonal Ethics Commission Bern 2016) and written patient consent from traumatic injured IVDs (30-55 years old, 6 male donors), which were classified as mildly degenerated (Pfirrmann grade 2-3). To ensure purity of AF samples, AF tissue was collected after removing all the adjacent NP tissue and cartilage EP. The collected AF tissue was incubated with red blood cell lysis buffer [155 mM $\mathrm{NH}_{4} \mathrm{Cl}, 10 \mathrm{M} \mathrm{KHCO}_{3}$ and $0.1 \mathrm{mM}$ EDTA in Milli-Q water] for $5 \mathrm{~min}$ on a shaker at room temperature and, then, washed with PBS. Then, the chopped tissue was enzymatically digested for $1 \mathrm{~h}$ with $0.2 \% \mathrm{w} / \mathrm{v}$ Pronase (Roche) in $\alpha \mathrm{MEM}$ (Gibco), followed by $12-14 \mathrm{~h}$ at $37^{\circ} \mathrm{C}$ in $130 \mathrm{U} / \mathrm{mL}$ collagenase type II (Worthington) in $\alpha \mathrm{MEM} / 10 \%$ FBS (PAN Biotech, Aidenbach, Germany). Single-cell suspension was obtained by filtering through a $100 \mu \mathrm{m}$ cell strainer. Next, cells were seeded at a concentration of 10,000 cells $/ \mathrm{cm}^{2}$ and expanded with $\alpha$ MEM supplemented with $10 \%$ FCS, $100 \mathrm{U} / \mathrm{mL}$ penicillin and $100 \mathrm{mg} / \mathrm{mL}$ streptomycin ( $1 \% \mathrm{P} / \mathrm{S}, \mathrm{Gibco})$. Incubation conditions were set to $5 \%$ $\mathrm{CO}_{2}$ at $37^{\circ} \mathrm{C}$ at a hypoxic condition of $2 \% \mathrm{O}_{2}$. Culture medium was changed twice a week and cells were detached at $\sim 80 \%$ confluence using a dissociation buffer composed of $0.05 \%$ trypsin/EDTA (Gibco) and $0.01 \%$ collagenase $\mathrm{P}$ (Roche) for $5 \mathrm{~min}$ at $37^{\circ} \mathrm{C}$. Cells were sub-cultured at a cell density of 3,000 cells $/ \mathrm{cm}^{2}$ for expansion in the same medium as above. Passage 2 AF cells were used in the present study.

\section{AF cells, 2D and 3D culture in vitro \\ $2 D$ culture in vitro}

Passage 2 human AF cells were treated with either basal medium [ $\alpha$ MEM, $5 \%$ FBS, $1 \%$ ITS+ (BD Biosciences), $1 \% \mathrm{P} / \mathrm{S}$ ] or TGF $\beta$ medium [basal medium with $5 \mathrm{ng} / \mathrm{mL}$ recombinant human TGF- $\beta 1$ (Fitzgerald, Acton, MA, USA)] for $4 \mathrm{~d}$. Then, cells were dissociated for gene expression analysis, contractility study or flow cytometry analysis. AF cells pre-treated with TGF $\beta$ medium for $4 \mathrm{~d}$ were used for in vitro $3 \mathrm{D}$ culture experiments and ex vivo organ culture experiments.

\section{$3 D$ culture in vitro}

PU scaffolds were pre-wetted for $1 \mathrm{~h}$ in $\alpha \mathrm{MEM}$ with $10 \%$ FBS under vacuum conditions. Medium was completely aspirated from the scaffolds, which were placed into $0.5 \mathrm{~mL}$ protein-low-binding Eppendorf tubes. Tubes were pre-coated for $1 \mathrm{~h}$ at $37{ }^{\circ} \mathrm{C}$ with $1 \%$ BSA (Gibco). TGF- $\beta 1$-treated
AF cells were harvested and resuspended with medium or Corning ${ }^{\circledR}$ Collagen I, rat tail solution at a cell density of $2 \times 10^{5}$ cells per $30 \mu \mathrm{L}$. The final concentration of the collagen I hydrogel was $1.81 \mathrm{mg} /$ $\mathrm{mL}$. For the TGF- $\beta 1$ containing group, 5 ng TGF- $\beta 1$ was added within the AF-cells-collagen I solution suspension. Cell suspension in medium or collagen I solution was dropped onto the scaffold $(30 \mu \mathrm{L}$ per scaffold). Scaffolds were compressed mildly with forceps to allow cell suspension infiltration into the scaffold, then incubated for $1 \mathrm{~h}$ at $37{ }^{\circ} \mathrm{C}$ to allow cell adhesion and collagen-hydrogel gelation. Next, constructs were transferred into a 24-well plate and cultured at $37{ }^{\circ} \mathrm{C}, 5 \% \mathrm{CO}_{2}, 2 \% \mathrm{O}_{2}$ in high-glucose DMEM supplemented with 1 \% P/S, 2 \% FBS, 50 mg/ $\mathrm{mL}$ L-ascorbic acid 2-phosphate (Sigma-Aldrich), $1 \%$ ITS+ and $1 \%$ NEAA (Gibco). The medium volume was $1 \mathrm{~mL}$ per scaffold and it was replaced twice a week. After $7 \mathrm{~d}$ of culture, scaffolds were collected for gene expression analysis, DNA and GAG quantification and toluidine blue staining. For the ex vivo organ culture study, constructs were immediately implanted into the AF defect after gelation of the collagen type I hydrogel.

\section{Bovine caudal IVD dissection}

Caudal IVDs were harvested from 6-12-monthold calves obtained from a local abattoir after sacrifice. Disc dissection was performed as described previously (Lang et al., 2018). IVDs with cartilage EPs were isolated using a band saw, then scraped using a scalpel to remove the vertebral bone and growth plate and ensure two parallel planes of disc. EP surfaces were cleaned with Ringer's balanced salt solution using a Pulsavac Wound Debridement Irrigation System (Zimmer, Minneapolis, MN, USA) to remove cutting debris and blood clots. IVDs were pre-washed in PBS with $10 \% \mathrm{P} / \mathrm{S}$ (Gibco) at room temperature for $20 \mathrm{~min}$, then cultured at $37{ }^{\circ} \mathrm{C} 5 \%$ $\mathrm{CO}_{2}$ in 6-well plates with $7.5 \mathrm{~mL}$ IVD culture medium: high-glucose DMEM supplemented with $1 \% \mathrm{P} / \mathrm{S}$, $50 \mathrm{mg} / \mathrm{mL}$ Primocin (Invitrogen), 2 \% FBS, $50 \mathrm{mg} /$ $\mathrm{mL}$ ascorbate-2phosphate, $1 \%$ ITS+ and $1 \%$ NEAA. Culture medium was replaced every day.

Different parts of healthy IVD tissue, including NP tissue (gel-like inner core of 6-8 mm diameter), outer AF tissue (oAF, distinguishable lamellar AF tissue, ring at thickness $\sim 4 \mathrm{~mm}$ ) and inner $\mathrm{AF}$ tissue (iAF, located between NP and oAF) from 6 bovine tails (age 6-12 months) were collected for gene expression analysis on day 0 , to measure the expression level of potential AF markers (Table 1).

\section{Annulotomy model for preclinical testing of AF repair therapy in whole-organ IVD culture}

24 caudal IVDs were dissected from 4 bovine tails (age 6-12 months). Day 0 control group comprised 4 IVDs. AF defect repair groups comprised 6 IVDs per group and consisted of 1) an acellular PU scaffoldcollagen hydrogel (PU-Col), 2) PU-Col with TGF- $\beta 1$ pre-treated AF cells (PU-Col-AFCs) and 3) PU-Col 
Table 1. Oligonucleotide primers and probes (bovine and human) used for qRT-PCR. Primers and probes with the sequence shown were custom designed; primers and probes with the catalogue number were from Applied Biosystems. fw: forward; rev: reverse; b: bovine; h: human.

\begin{tabular}{|c|c|c|}
\hline Gene & Primer/probe type & Sequence \\
\hline \multirow{3}{*}{ bCOL1A2 } & Primer fw $\left(5^{\prime}-3^{\prime}\right)$ & TGC AGT AAC TTC GTG CCT AGC A \\
\hline & Primer rev $\left(5^{\prime}-3^{\prime}\right)$ & CGC GTG GTC CTC TAT CTC CA \\
\hline & Probe (5'FAM/3'TAMRA) & CAT GCC AAT CCT TAC AAG AGG CAA CTG C \\
\hline \multirow{3}{*}{$b C O L 2 A 1$} & Primer fw $\left(5^{\prime}-3^{\prime}\right)$ & AAG AAA CAC ATC TGG TTT GGA GAA A \\
\hline & Primer rev $\left(5^{\prime}-3^{\prime}\right)$ & TGG GAG CCA GGT TGT CAT C \\
\hline & Probe (5'FAM/3'TAMRA) & CAA CGG TGG CTT CCA CTT CAG CTA TGG \\
\hline \multirow{3}{*}{ bACAN } & Primer fw $\left(5^{\prime}-3^{\prime}\right)$ & CCA ACG AAA CCT ATG ACG TGT ACT \\
\hline & Primer rev $\left(5^{\prime}-3^{\prime}\right)$ & GCA CTC GTT GGC TGC CTC \\
\hline & Probe (5'FAM/3'TAMRA) & ATG TTG CAT AGA AGA CCT CGC CCT CCA T \\
\hline \multirow{3}{*}{ bMMP3 } & Primer fw $\left(5^{\prime}-3^{\prime}\right)$ & GGC TGC AAG GGA CAA GGA A \\
\hline & Primer rev $\left(5^{\prime}-3^{\prime}\right)$ & CAA ACT GTT TCG TAT CCT TTG CAA \\
\hline & Probe (5'FAM/3'TAMRA) & CAC CAT GGA GCT TGT TCA GCA ATA TCT AGA AAA C \\
\hline \multirow{3}{*}{ bADAMTS5 } & Primer fw $\left(5^{\prime}-3^{\prime}\right)$ & GAT GGT CAC GGT AAC TGT TTG CT \\
\hline & Primer rev $\left(5^{\prime}-3^{\prime}\right)$ & GCC GGG ACA CAC CGA GTA C \\
\hline & Probe (5'FAM/3'TAMRA) & AGG CCA GAC CTA CGA TGC CAG CC \\
\hline$b C D 146$ & & Bt03258894_m1 \\
\hline$b S M 22 \alpha$ & & Bt03234600_m1 \\
\hline$b S C X$ & & Hs03054634_g1 \\
\hline bMKX & & Bt04292311_m1 \\
\hline$b E L N$ & & Bt03216594_m1 \\
\hline bVCAN & & Bt03217632_m1 \\
\hline bRPLPO & & Bt03218086_m1 \\
\hline \multirow{3}{*}{ hCOL1A1 } & Primer fw $\left(5^{\prime}-3^{\prime}\right)$ & CCC TGG AAA GAA TGG AGA TGA T \\
\hline & Primer rev $\left(5^{\prime}-3^{\prime}\right)$ & ACT GAA ACC TCT GTG TCC CTT CA \\
\hline & Probe (5'FAM/3'TAMRA) & CGG GCA ATC CTC GAG CAC CCT \\
\hline \multirow{3}{*}{$h C O L 2 A 1$} & Primer fw $\left(5^{\prime}-3^{\prime}\right)$ & GGC AAT AGC AGG TTC ACG TAC A \\
\hline & Primer rev $\left(5^{\prime}-3^{\prime}\right)$ & GAT AAC AGT CTT GCC CCA CTT ACC \\
\hline & Probe (5'FAM/3'TAMRA) & CCT GAA GGA TGG CTG CAC GAA ACA TAC \\
\hline \multirow{3}{*}{ hACAN } & Primer fw $\left(5^{\prime}-3^{\prime}\right)$ & AGT CCT CAA GCC TCC TGT ACT CA \\
\hline & Primer rev $\left(5^{\prime}-3^{\prime}\right)$ & CGG GAA GTG GCG GTA ACA \\
\hline & Probe (5'FAM/3'TAMRA) & CCG GAA TGG AAA CGT GAA TCA GAA TCA ACT \\
\hline hMMP3 & & Hs00968305_m1 \\
\hline hADAMTS5 & & Hs01095518_m1 \\
\hline$h C D 146$ & & Hs00174838_m1 \\
\hline$h S M 22 \alpha$ & & Hs00162558_m1 \\
\hline$h S C X$ & & Hs03054634_g1 \\
\hline$h M K X$ & & Hs00543190_m1 \\
\hline$h E L N$ & & Hs00355783_m1 \\
\hline hVCAN & & Hs00171642_m1 \\
\hline \multirow{3}{*}{ hRPLPO } & Primer fw $\left(5^{\prime}-3^{\prime}\right)$ & TGG GCA AGA ACA CCA TGA TG \\
\hline & Primer rev $\left(5^{\prime}-3^{\prime}\right)$ & CGG ATA TGA GGC AGC AGT TTC \\
\hline & Probe $\left(5^{\prime}\right.$ FAM/3'TAMRA) & AGG GCA CCT GGA AAA CAA CCC AGC \\
\hline
\end{tabular}


with TGF- $\beta 1$ pre-treated AF cells and 5 ng TGF- $\beta 1$ (PU-Col-AFCs-TGF $\beta$ ). Within the 6 replicates in each group, 4 IVDs were used for gene expression analysis of human AF cells in scaffold and native IVD tissue and 2 IVDs were used for safranin O/fast green staining. 2 IVDs served as non-repair negative control on day 15 and were used for safranin $\mathrm{O} /$ fast green staining.

The IVD AF defect was created with a biopsy punch (diameter $3 \mathrm{~mm}$, length $7 \mathrm{~mm}$ ). Full thickness of AF tissue and some NP tissue were removed. Then, the defect was refilled with different scaffolds, as described above. A PU membrane $(12 \times 7 \mathrm{~mm})$ was affixed to the IVD with $2 \mu \mathrm{L}$ of EPIGLU ${ }^{\circledR}$ (MeyerHaake $\mathrm{GmbH}$, Ober-Mörlen, Germany) surrounding the defect area, to maintain the scaffold within the defect. IVDs were cultured in IVD culture medium and loaded with physiological compressive loading for $1 \mathrm{~h}$ at $0.02-0.2 \mathrm{MPa}, 0.2 \mathrm{~Hz}$ daily within a bioreactor (Lang et al., 2018). The disc height was measured using a caliper at 2 positions to calculate percentage change normalised to day 0 after dissection. After $14 \mathrm{~d}$ of culture, IVDs were collected for evaluations.

\section{Flow cytometry analysis}

TGF- $\beta 1$-treated and -non-treated AF cells were harvested by trypsinisation. Single-cell suspension was prepared at a cell density of $1 \times 10^{5}$ cells per $100 \mu \mathrm{L}$ staining buffer (PBS with $0.2 \%$ BSA and $1 \mathrm{mM}$ EDTA). Cell suspensions were incubated at $4{ }^{\circ} \mathrm{C}$ in the dark for $30 \mathrm{~min}$ with $10 \mu \mathrm{L}$ fluorescenceconjugated mouse monoclonal anti-human CD146 antibody (CD146-APC, human, Miltenyi Biotec) or $10 \mu \mathrm{L}$ mouse IgG1-APC (isotype control, Miltenyi Biotech). After incubation and washing, DAPI at a final concentration of $0.1 \mu \mathrm{g} / \mathrm{mL}$ was added for live/dead staining. Flow cytometric analysis was performed on a FACS AriaIII (BD Biosciences) and at least 30,000 events per sample were recorded. Data analysis was performed using BD FACSDiva software. A gating strategy was used to exclude dead cells and cell doublets.

\section{Gene expression analysis}

RNA isolation from 2D-cultured AF cell samples was performed using TRI reagent (Molecular Research Centre Inc., Cincinnati, OH, USA) according to the manufacturer's protocol. AF cells in PU scaffoldcollagen type I hydrogel constructs were placed into $1 \mathrm{~mL}$ TRI reagent with $5 \mu \mathrm{L}$ polyacryl carrier (Molecular Research Centre Inc.) and homogenised by a tissue-lyser (Retsch $\mathrm{GmbH}$, Haan, Germany). After centrifugation at $12,000 \times g$ for $15 \mathrm{~min}$, the supernatant was collected in a fresh EP tube and the RNA isolation was performed according to the manufacturer's protocol. Native IVD tissues, including NP and AF in intact discs, as well as AF tissue adjacent and opposite to the repair constructs, were collected on day 0 and 14. Tissues of 150-200 mg/sample were cut into small pieces and snap-frozen by liquid nitrogen and hammering (Caprez Stephanie, 2018). Then, tissues were transferred into $3 \mathrm{~mL}$ TRI reagent with $15 \mu \mathrm{L}$ polyacryl carrier. Samples were homogenised using a tissue-lyser. After centrifugation, the supernatant was extracted by phase separation by adding $100 \mu \mathrm{L}$ bromochloropropane per $1 \mathrm{~mL}$ of TRI reagent. The aqueous phase after centrifugation was transferred to a fresh tube and mixed with the same volume of $70 \%$ ethanol. Then, RNA isolation was performed using the QIAGEN RNeasy MINI kit according to the manufacturer's protocol. Reverse transcription was performed using SuperScript ${ }^{\circledR}$ VILO $^{\text {TM }}$ cDNA Synthesis Kit (Invitrogen).

qRT-PCR was conducted on QuantStudio6 System (Applied Biosystems). Sequences of the primers and probes used in qRT-PCR of bovine and human cells/ tissue are listed in Table 1. RPLP0 ribosomal RNA was used as endogenous control. Data were analysed using the $2^{-\triangle \Delta C T}$ method.

\section{Cell contraction functionality assay}

Contractility of TGF- $\beta 1$-treated and -non-treated cells was evaluated by a cell contraction assay in collagen I hydrogel. A 24-well plate was coated with $1 \%$ BSA and incubated at $37^{\circ} \mathrm{C}$ for at least $1 \mathrm{~h}$. Cells from 3 donors were encapsulated in $1.81 \mathrm{mg} / \mathrm{mL}$ type I collagen with 4 technical replicates at a seeding density of $1.5 \times 10^{5}$ cells $/ \mathrm{mL}$. Cells were cultured at $37{ }^{\circ} \mathrm{C} 2 \% \mathrm{O}_{2}$ in $\alpha \mathrm{MEM}$ with $10 \%$ FBS. After $24 \mathrm{~h}$, gels were photographed (Canon PowerShot SX50 HS) and well and gel diameters measured using NISElements D 3.2 (NIKON Japan). Two gel diameters were averaged to calculate the gel area. The gel area after $24 \mathrm{~h}$ was divided by the well area, calculated from the well diameter.

\section{Toluidine blue staining}

Cell distribution and ECM deposition within PU scaffold with or without hydrogel were evaluated by toluidine blue staining. Samples at day 1 and 7 were snap-frozen in cryo-compound (Leica). Vertical sections of scaffold were made at a thickness of $12 \mu \mathrm{m}$. Slides were fixed in $70 \%$ methanol for $10 \mathrm{~min}$, $100 \%$ methanol for $10 \mathrm{~min}$, dried overnight, stained with $0.1 \%$ toluidine blue for $2 \mathrm{~min}$ and rinsed with deionised water (4-5 times).

\section{Safranin O/fast green staining}

IVD samples after $14 \mathrm{~d}$ of culture were snap-frozen in cryo-compound after removal of the cartilage EP from one side. IVD transverse cryo-sections were made at a thickness of $12 \mu \mathrm{m}$. Slices were fixed as above, stained with $0.1 \%$ safranin $\mathrm{O}$ and $0.02 \%$ fast green to reveal proteoglycan and collagen deposition, respectively, and counterstained with Weigert's haematoxylin to reveal cells distribution (Lang et al., 2018).

Cell density in the implanted constructs was calculated using the safranin $\mathrm{O} /$ fast green-stained images. High-magnification images $(676 \times 536 \mu \mathrm{m})$ were taken at 6 random positions of each slide, with 
2 slides per IVD and 2 IVDs per group. In total, cells from 24 images of each group were counted by Image J 1.52a (NIH).

\section{GAG and DNA content measurement}

Cell-scaffold constructs after $7 \mathrm{~d}$ of culture were digested overnight at $56{ }^{\circ} \mathrm{C}$ with $0.5 \mathrm{mg} / \mathrm{mL}$ proteinase K (Roche, Mannheim, Germany) solution. DNA content was measured using the PicoGreen kit (Invitrogen) according to the manufacturer's instruction. GAG content was determined by dimethylmethylene blue assay (1.9-DMMB; SigmaAldrich).

\section{Statistical analysis}

Statistical analyses were performed using GraphPad Prism 7 software (GraphPad Software, Inc., La Jolla, CA, USA). D'Agostino-Pearson omnibus normality test was used to define whether the data were normally distributed. For data that were normally distributed, unpaired $t$-test was used to determine differences between two groups; one-way ANOVA was used to determine differences between three or more groups. For data that were not normally distributed, Mann-Whitney U test was used to determine differences between two groups; Kruskal Wallis test was used to determine differences between three or more groups. $p<0.05$ was considered statistically significant.

\section{Results}

\section{Phenotype markers of AF cells}

Phenotype markers of AF cells were defined by comparison of the gene expression levels in different parts of bovine IVD tissue. Compared with NP tissue and iAF, oAF expressed higher levels of COL1A2 $(p<0.05), C D 146(p<0.05), S M 22 \alpha(p<0.05)$ and MKX $(p<0.05)$ (Fig. 1), which were, therefore, defined as phenotype markers of healthy and functional AF cells. Furthermore, oAF tissue expressed lower levels of COL2A1 $(p<0.001), A C A N(p<0.001)$ and SCX $(p<0.001)$ as compared with NP tissue. Interestingly, the transient zone iAF tissue showed a comparable gene expression pattern to NP tissue, except for lower levels of CD146 $(p<0.001)$.

\section{Induction of the functional human AF cell} phenotype for AF repair - in vitro $2 \mathrm{D}$ culture

To evaluate the functional phenotype of human AF cells induced by TGF- $\beta 1$, gene expression levels of the AF markers were measured in human AF cells cultured with or without $5 \mathrm{ng} / \mathrm{mL}$ TGF- $\beta 1$ for $4 \mathrm{~d}$, since cells reached 70-80\% confluency after $4 \mathrm{~d}$ of culture, which is the optimal time point for cell trypsinisation and seeding on to the scaffold (Fig. 2a). mRNA levels of CD146 ( $p<0.05)$, SM22a $(p<0.01), S C X(p<0.01), M K X(p<0.01)$ and COL $2 A 1$ $(p<0.01)$ were significantly upregulated by TGF- $\beta 1$ treatment. CD146 upregulation at the protein level was confirmed by flow cytometry (Fig. 2b,c). The percentage of CD146 cells in 4 donors was $30.50 \pm 14.55 \%$ in basal medium, which increased to $72.25 \pm 22.02 \%$ in TGF $\beta$ medium. In contrast, ECM degrading enzymes, MMP3 $(p<0.001)$ and ADAMTS5 $(p<0.001)$, were downregulated by TGF- $\beta 1$ treatment (Fig. 2a). Cell contractility was determined in collagen I hydrogel by measuring the surface area of the collagen gel after $24 \mathrm{~h}$ of incubation, as a functionality test. TGF $\beta$ medium induced a larger reduction of the gel area $(22.8 \pm 8.1 \%)$ as compared with basal medium $(38.3 \pm 5.9 \%)$ (Fig. 2 d,e), which indicated a higher cell contractility after TGF- $\beta 1$ treatment.

\section{Preservation of the functional human AF cells} phenotype for AF repair - in vitro 3D culture To assess cell phenotype and tissue construction capabilities of induced functional human AF cells in an in vitro 3D model, human AF cells pre-treated with TGF- $\beta 1$ for $4 \mathrm{~d}$ were seeded on to PU scaffold only (PU-AFCs) or PU scaffold-collagen I hydrogel constructs with (PU-Col-AFCs-TGF $\beta$ ) or without (PU-Col-AFCs) 5 ng TGF- $\beta 1$ supplement. Gene expression was measured at day 7 , cell proliferation and matrix production both at day 1 and 7 after cell

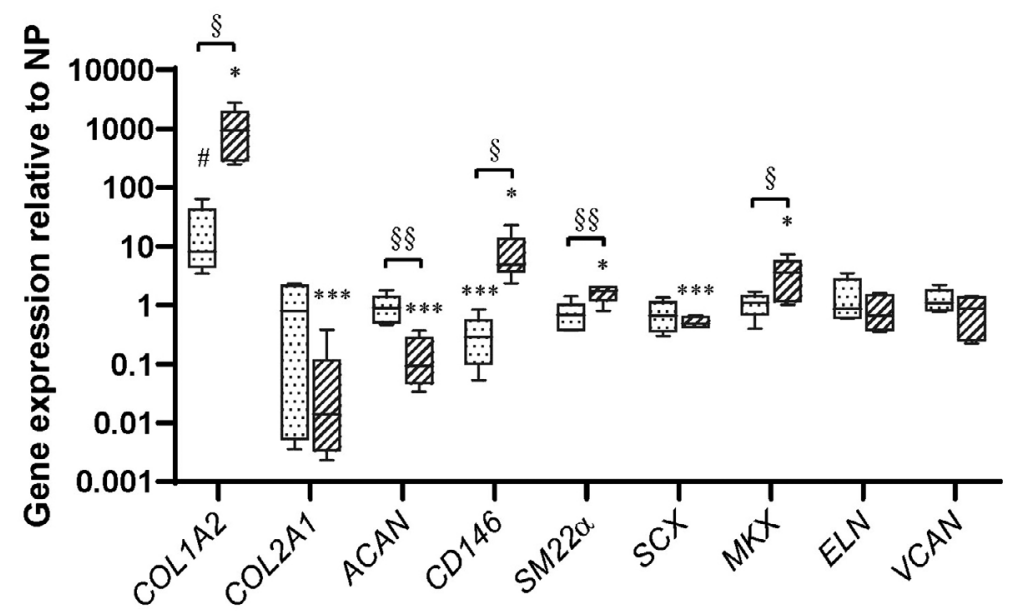

$\square$ iAF
Fig. 1. Relative mRNA expression in NP, iAF and oAF from healthy bovine IVDs. Data were normalised to the expression level of NP tissue. $n=6,{ }^{*} p<0.1,{ }^{*} p<0.05,{ }^{* * *} p<0.001$ vs. gene expression level in NP, $\$ p<0.05$, $\S \& p<0.01$ comparing iAF and oAF. 
seeding, to investigate the effect of the cell carrier on functional AF cell phenotype maintenance and AF tissue regeneration.

AF cells were evenly distributed in the PU scaffold both with or without collagen I hydrogel at day 1 after seeding (Fig. 3a-c). After $7 \mathrm{~d}$ of culture, higher cell density and more intense ECM staining were observed in PU-Col-AFCs-TGF $\beta$ (Fig. 3f) as compared to the other two groups (Fig. 3d,e), especially around the outer surface of the PU scaffold. Furthermore, DNA and GAG content and GAG/DNA ratio were significantly higher in the PU-Col-AFCsTGF $\beta$ scaffold when compared with PU-Col-AFCs (Fig. 3g-i). When comparing day 7 with day 1, DNA and GAG content and GAG/DNA ratio increased only in the PU-Col-AFCs-TGF $\beta$ group.

Gene expression levels were evaluated in PUAFCs, PU-Col-AFCs and PU-Col-AFCs-TGF $\beta$ after
$7 \mathrm{~d}$ of culture and data were normalised to PU-AFCs. AF cells in PU-Col-AFCs and PU-Col-AFCs-TGF $\beta$ expressed higher levels of COL2A1, CD146, SM22a, $S C X$ and $M K X$ and lower levels of MMP3 and ADAMTS5 when compared with PU-AFCs (Fig. $4)$. TGF- $\beta 1$ supplementation into the PU scaffoldcollagen I hydrogel did not further affect the gene expression profile of AF cells as compared with the PU-Col-AFCs group.

\section{AF rupture repair - preclinical testing in ex vivo IVD organ culture system}

To test the property of the constructs in a preclinical organ culture model, annulotomised IVDs were repaired with PU scaffold-collagen hydrogel (PUCol) or PU-Col with AF cells with (PU-Col-AFCsTGF $\beta$ ) or without (PU-Col-AFCs) 5 ng TGF- $\beta 1$. Then, IVDs were cultured under physiological

a

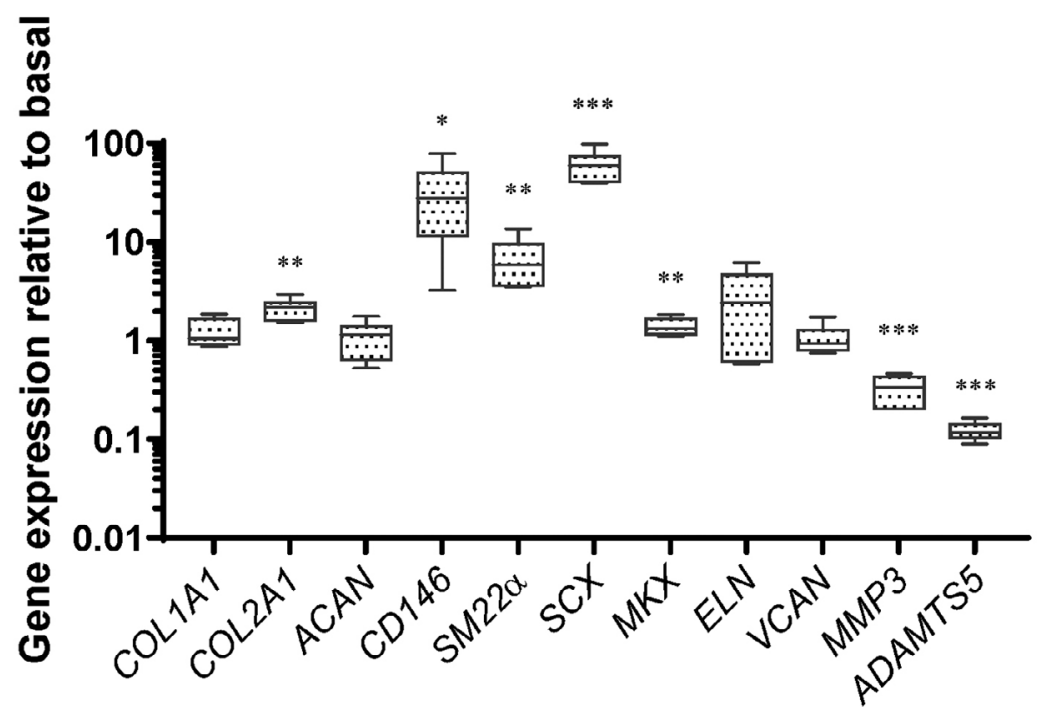

b

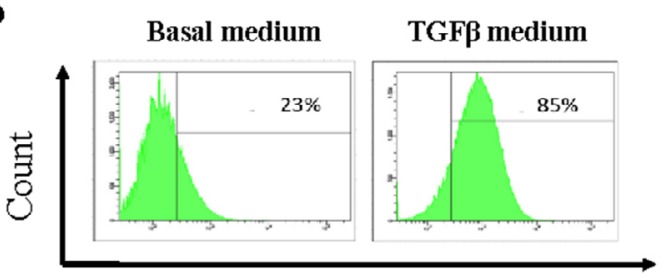

CD146+ stain intensity

d

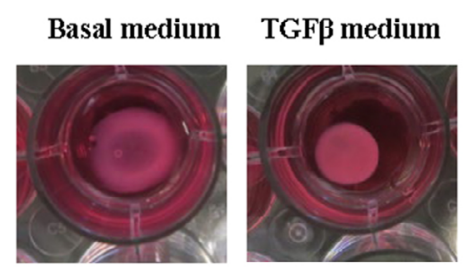

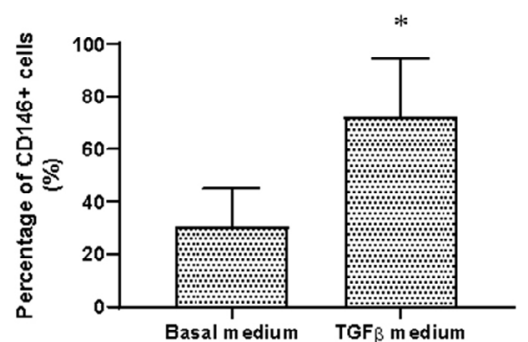

e

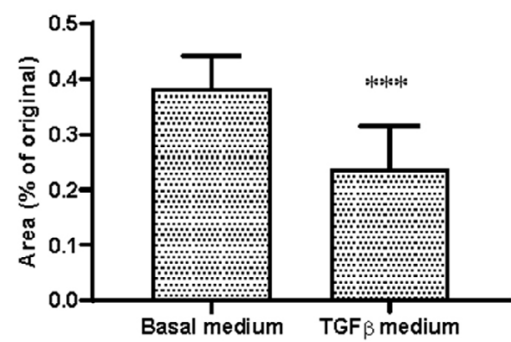

Fig. 2. Phenotype of human AF cells after treatment with TGF- $\beta 1$ for $\mathbf{4} \mathbf{d}$. (a) Relative mRNA expression, data were normalised to basal medium. (b) Representative and (c) average percentage of CD146 ${ }^{+}$cells detected by flow cytometry. (d,e) Cell contractibility of AF cells cultured with basal or TGF $\beta$ medium. Mean $+\mathrm{SD} ; n=4,{ }^{*} p<0.05,{ }^{* *} p<0.01,{ }^{* * *} p<0.001$ vs. cells treated with basal medium. 
loading condition for 2 weeks, mimicking the in situ microenvironment for testing of AF rupture repair. The disc height change was measured during the whole culture period (Fig. 5). At day 2, disc height slightly increased for all groups after overnight free swelling as compared with day 0. Dynamic loading for $1 \mathrm{~h}$ caused a physiological disc height loss in all groups repaired with implants: PU-Col $8.6 \pm 2.9 \%$, PU-Col-AFCs $8.6 \pm 1.0 \%$, PU-Col-AFCs-TGF $\beta$ $6.8 \pm 1.4 \%$. After $14 \mathrm{~d}$ of repetitive dynamic loading, IVDs showed about $2 \%$ of further disc height loss: PU-Col $10.8 \pm 1.9 \%$, PU-Col-AFCs $10.2 \pm 1.5 \%$, PU-Col-AFCs-TGF $\beta 8.4 \pm 2.2 \%$. However, all IVDs recovered after free swelling. After $15 \mathrm{~d}$ culture with daily dynamic loading, no significant disc height loss was observed. Cell implantation and TGF- $\beta 1$ supplementation did not show any effect on disc height change under dynamic loading.

Safranin O/fast green staining of transverse IVD sections after $15 \mathrm{~d}$ of culture is shown in Fig. 6. Part of the NP tissue protruded into the AF defect region in the injury control group without repair (Fig. 6a). In all IVDs repaired with PU scaffold-collagen hydrogel (PU-Col cell-free, PU-Col-AFCs and PUCol-AFCs-TGF $\beta$ ), NP tissue was maintained in its native position (Fig. 6b-d). When the AF defect was repaired with PU-Col scaffold without AF cells (Fig. $6 \mathbf{b}, \mathbf{e})$, after $15 \mathrm{~d}$ of culture, no fast-green staining could be detected at the defect site. When the defect was repaired with PU-Col scaffold with AF cells (Fig. $6 \mathrm{c}, \mathbf{f})$, AF cells were found in the scaffold after $15 \mathrm{~d}$ of culture. Collagen staining with fast green was
Day 1 PU-AFCs

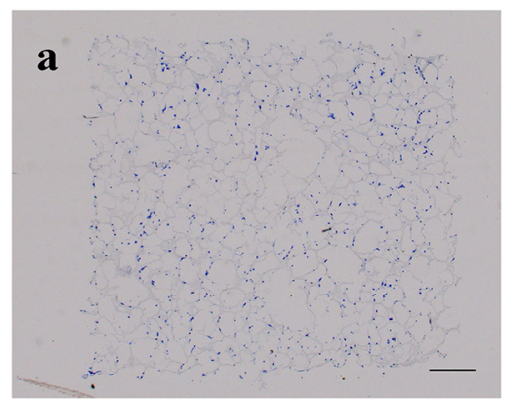

Day 7 PU-AFCs

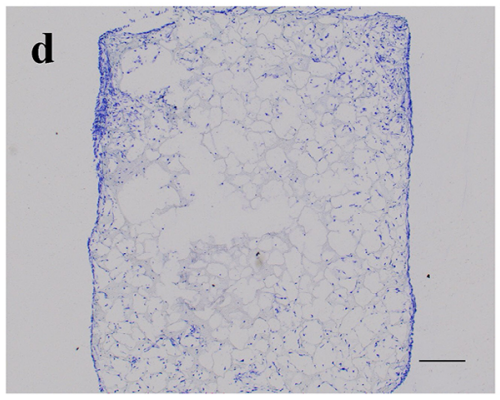

g

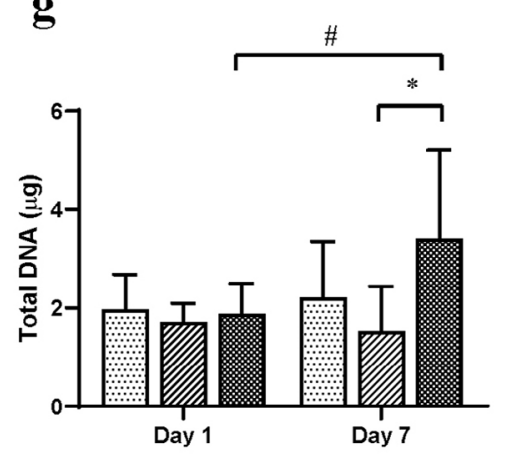

Day 1 PU-Col-AFCs

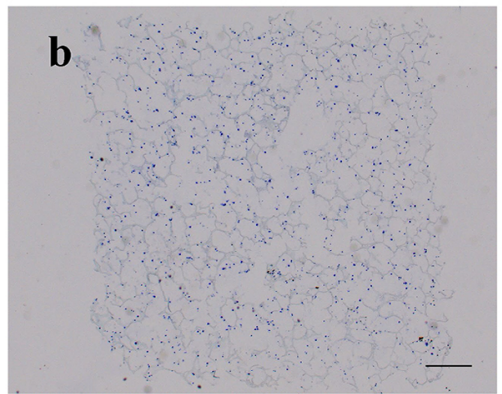

Day 7 PU-Col-AFCs

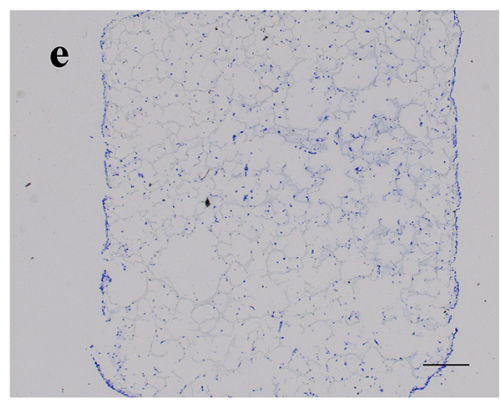

h

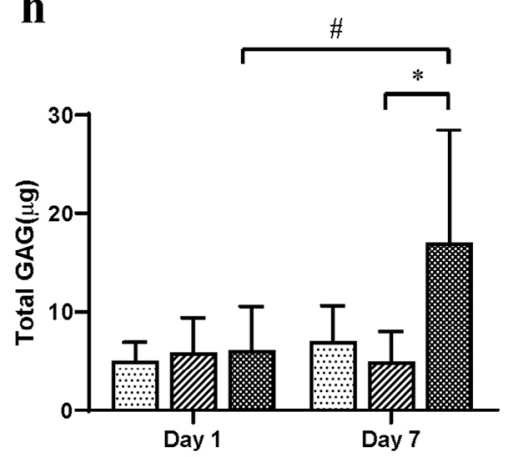

Day 1 PU-Col-AFCs-TGFß

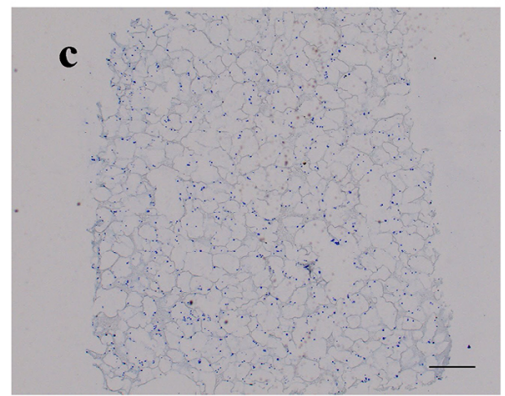

Day 7 PU-Col-AFCs-TGFß

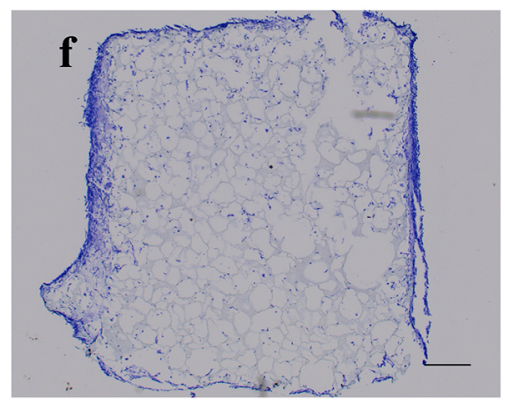

i

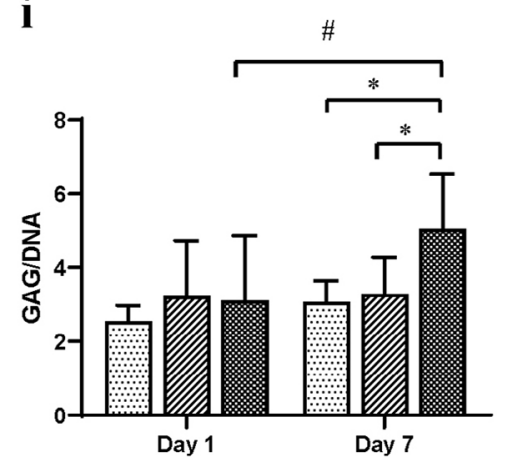

\section{PU-AFCs}

Fig. 3. 3D culture of human AF cells in vitro. (a-f) Representative toluidine-blue-stained sections of scaffolds. TGF- $\beta 1$-pre-treated human AF cells seeded on to (a,d) scaffolds PU-AFCs, (b,e) PU-Col-AFCs and (c,f) PU-Col-AFCs-TGF $\beta$ after 1 and 7 d. Scale bar: $500 \mu \mathrm{m}$. (g) DNA content, (h) GAG content and (i) GAG/DNA ratio in scaffolds after 1 and $7 \mathrm{~d}$ of culture. Mean $+\mathrm{SD}, n=6,{ }^{*} p<0.1,{ }^{*} p<0.05$. 

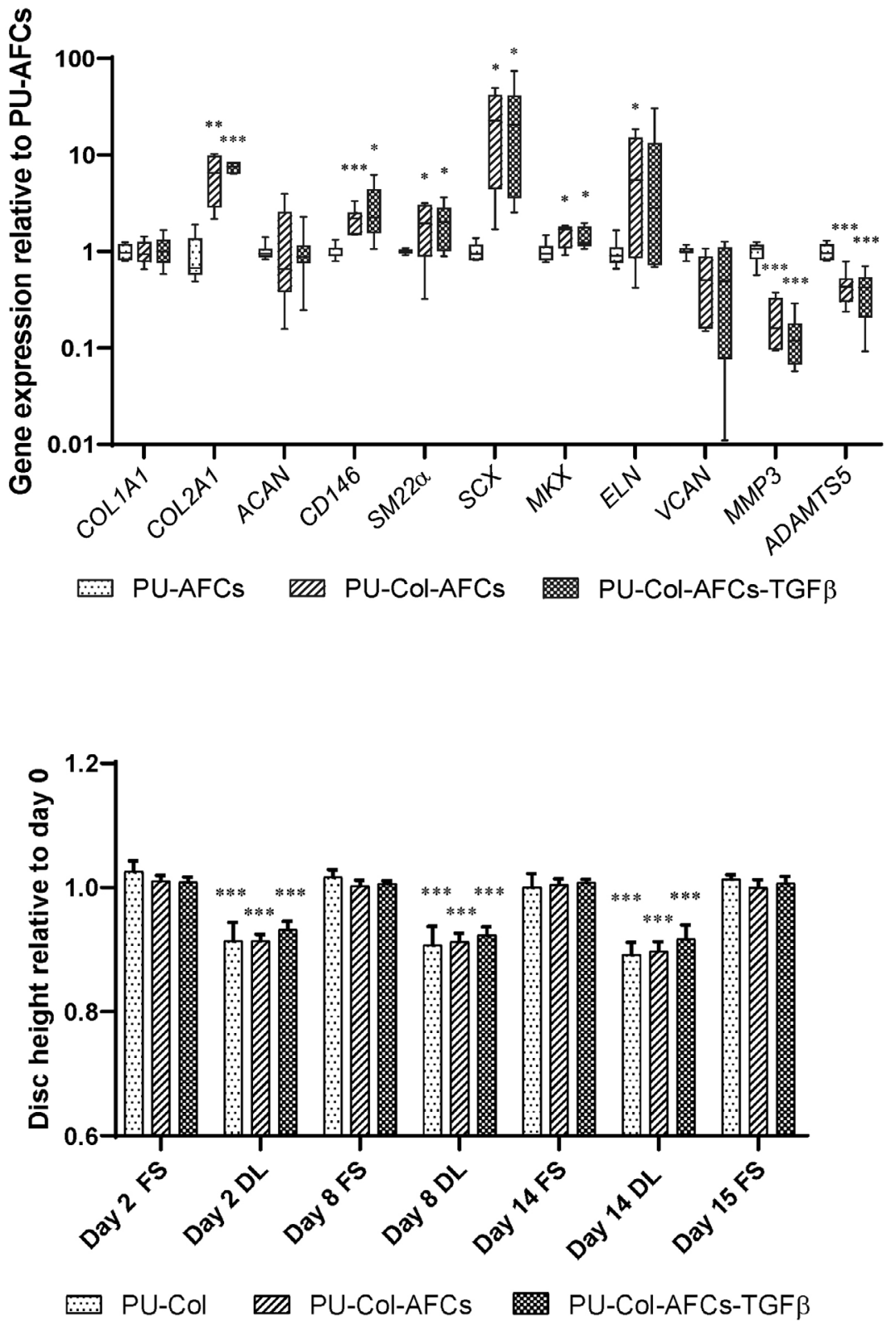

Fig. 4. Gene expression of human AF cells 3D-cultured in vitro. Relative mRNA expression of TGF- $\beta 1$-pre-treated human AF cells seeded on to PU scaffold only (PU-AFCs), PU scaffold-collagen I hydrogel construct (PU-Col-AFCs) and PU-Col scaffold supplemented with 5 ng TGF- $\beta 1$ (PU-Col-AFCsTGF $\beta$ ) after $7 \mathrm{~d}$ of culture. Data were normalised to expression level of PU-AFCs. $n=6,{ }^{*} p<0.05$, ** $p<0.01,{ }^{* * *} p<0.001$ vs. gene expression levels of PU-AFCs.
Fig. 5. Disc height change during $15 \mathrm{~d}$ organ culture. Disc height change relative to initial dimension after dissection (day 0) at different time points: after free swelling culture overnight and after dynamic loading over $15 \mathrm{~d}$ of organ culture. PU-Col: annulotomised IVDs implanted with PU-Col scaffold; PU-Col-AFCs: PU-Col scaffold seeded with AF cells; PU-Col-AFCsTGF $\beta$ : PU-Col-AFCs supplemented with TGF- $\beta 1$. Mean + SD, $n=6$. ${ }^{* * *} p<0.001$ vs. disc height on day 0 . also detected at the defect site. Furthermore, when TGF- $\beta 1$ was supplemented in the collagen hydrogel (Fig. 6d,g), a higher cell density and stronger collagen staining intensity was observed at the defect site. The average cell number in high magnification visual fields was significantly higher in PU-Col-AFCs-TGF $\beta$ as compared with PU-Col-AFCs $(p<0.001)$ (Fig. 6h).

Gene expression levels of implanted AF cells after $15 \mathrm{~d}$ of organ culture was analysed (Fig. 7). Results showed that COL1A1 $(p<0.01)$ expression was significantly higher in PU-Col-AFCs-TGF $\beta$ as compared with PU-Col-AFCs, which correlated with the fast green staining results. There was also a trend for increased CD146 $(p<0.1)$ and ELN $(p<0.1)$ expression by TGF- $\beta 1$ supplementation in the collagen gel. Gene expression levels in the native IVD tissues, including AF close to PU scaffold, NP tissue and AF opposite PU scaffold, were also measured after $15 \mathrm{~d}$ of organ culture. No significant difference was found among the 3 repaired groups (Fig. 8).

\section{Discussion}

There is an unmet clinical need for AF rupture repair, especially for large AF defects. Tissue engineering AF for large AF rupture repair is considered to be a promising approach to prevent disc re-herniation and associated discogenic pain and to reconstitute the disc biological and mechanical function (Chu et al., 2018; Iatridis et al., 2013; Sloan et al., 2018).

A clear understanding of markers related to the healthy and functional AF cell phenotype is fundamental to define proper cell sources for AF tissue regeneration. However, there is surprisingly limited research on AF cell phenotype so far (Pattappa et al., 2012; Torre et al., 2019). In the current study, the expression profile of several potential phenotypic markers of functional AF cells was measured in healthy oAF tissue as compared with iAF and NP tissue. COL1A2, CD146, SM22 $\alpha$ and MKX were most highly expressed in the oAF (Fig. 1). Thus, 
they were defined as markers of functional AF cells (Bron et al., 2009; Costi et al., 2007; Nakamichi et al., 2016; Schmidt et al., 2007). Each of these markers had previously been shown to be related to AF tissue function. Collagen type I expression at both gene and protein level is a well-known marker of AF cells in all species related with the tissue ECM property, since the proportion of collagen type I increases from the NP towards the outer AF (Bron et al., 2009). MKX expression at both gene and protein level has recently been identified as a transcription factor for AF cell differentiation, where MKX knock-out mice showed a much smaller collagen fibril diameter and a more rapid IVD degeneration as compared with the wild type mice (Nakamichi et al., 2016). Nakai et al. (2016) found that CD146 and SM22 $\alpha$ are co-expressed in the mouse oAF tissue, which may be correlated with the maximum shear strain in the oAF tissue under lateral bending of IVD (Costi et al., 2007; Schmidt et al., 2007). Interestingly, the expression level of CD146 in iAF was significantly lower than in NP. The exact reason is unclear, since few studies have reported CD146 expression in NP tissue and in iAF tissue. Milinos et al. (2015) found that $22.3 \%$ of bovine primary NP cells are positive for CD146 FACS staining, while in human primary NP cells, CD146 expression is not detected on the cell surface (Sakai et al., 2012). Based on the results from the current study, CD146 may serve as a candidate marker to distinguish NP and iAF. However, further studies are needed with a larger sample size and the protein expression should be confirmed. The current study, for the first time, systematically measured and identified these molecules as a marker pool for functional AF cells. These markers were defined in healthy bovine tissue due to very limited access to healthy human IVD tissue with good zonal structures. Some of the markers have been reported to be relevant to AF function in human and other species, as discussed above. Therefore, they were expected to be similar between bovine and human species and were used as a guideline for cell induction with human AF cells.

In previous studies, TGF- $\beta 1$ was shown to increase collagen type I and II as well as GAG production in a rat foetal AF cell micromass model; additionally, it tended to promote cell proliferation (Hayes and Ralphs, 2011). Blanquer et al. (2017) reported that TGF- $\beta 3$ is essential to support AF differentiation of human adipose stem cells. However, the effects of TGF- $\beta$ on the functional properties of AF cells and cell fate of MSCs were not clear, as markers of functional AF cells were not tested in those studies. The present study results corroborated the hypothesis that TGF- $\beta 1$ induced a functional AF cell phenotype in human mildly degenerated AF cells, as indicated by upregulated expression of phenotypic markers (CD146, SM22 $\alpha$ and MKX) and increased cell contractility. These results indicated that TGF$\beta 1$-induced AF cells from mildly degenerated disc tissue may be used as a cell source for AF rupture repair. It would be meaningful to further investigate the effect of TGF- $\beta 1$ on AF phenotype differentiation of MSCs under an appropriate microenvironment, which may expand the cell source options with an easily accessible endogenous cell type.

Interestingly, results showed that TGF- $\beta 1$ induced COL2A1 expression in human AF cells under in vitro 2D culture condition (Fig. 2a). However, in the $e x$

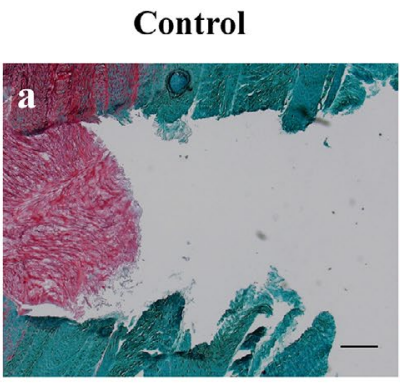

PU-Col cell-free

PU-Col-AFCs

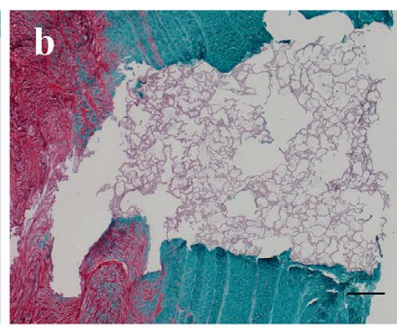

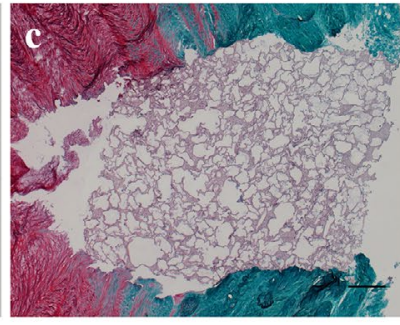

\section{PU-Col-AFCs-TGF $\beta$}

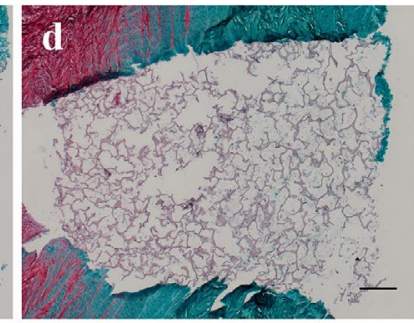

h

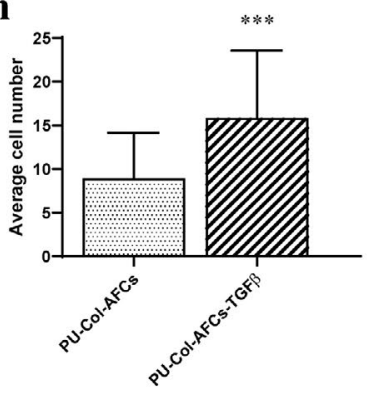

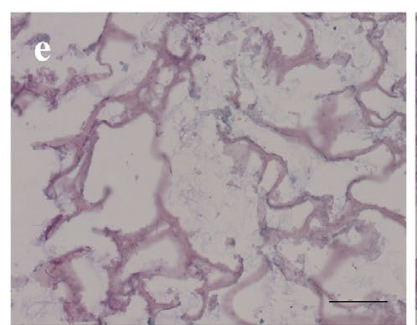
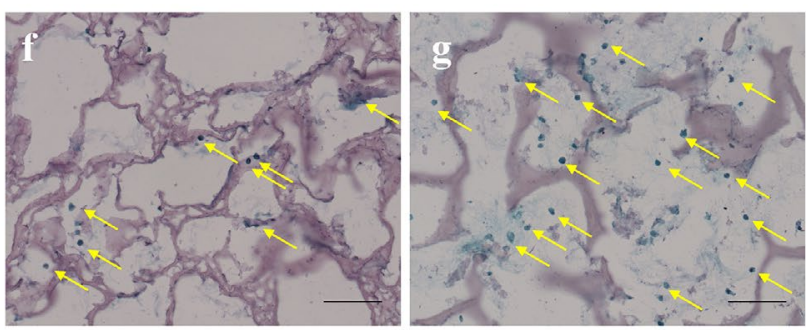

Fig. 6. Representative safranin O/fast green-stained sections of IVDs after 15 d organ culture. (a) Annulotomised discs and annulotomised discs repaired with (b,e) PU-Col cell-free, (c,f) PU-Col scaffold seeded with TGF- 31 -pre-treated AF cells (PU-Col-AFCs) and (d,g) PU-Col-AFCs supplemented with TGF- $\beta 1$ (PU-Col-AFCs TGF $\beta$ ), cultured for $15 \mathrm{~d}$ under dynamic load. (h) Cell numbers counted from the high magnification images in safranin O/fast green-stained sections. Mean $+\mathrm{SD}, n=24,{ }^{* * *} p<0.001$ vs. PU-Col-AFCs. Scale bar: (a-d) $500 \mu \mathrm{m},(\mathbf{e}-\mathbf{g}) 100 \mu \mathrm{m}$. Yellow arrows indicate cells. 


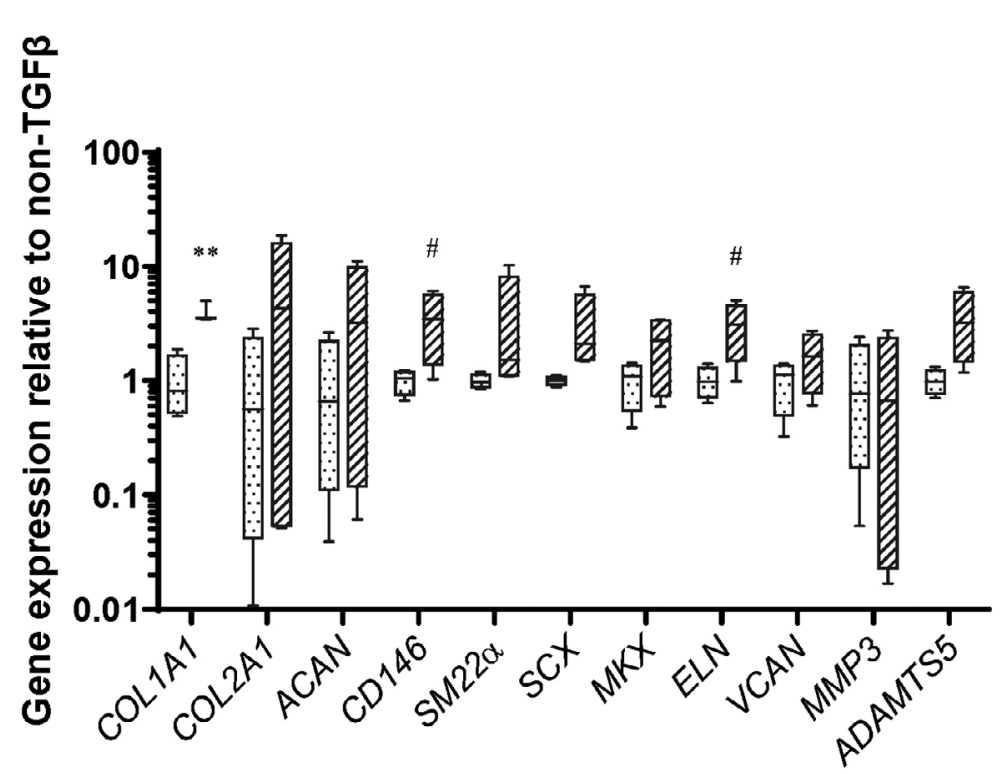

… PU-Col-AFCs
Fig. 7. Relative mRNA expression of human AF cells which were encapsulated in implants after $15 \mathrm{~d}$ organ culture. AF cells were encapsulated in PU-Col scaffold (PU-Col-AFCs) or PUCol scaffold supplemented with TGF- $\beta 1$ (PU-Col-AFCs-TGF $\beta$ ) and implanted into AF defect, cultured for $15 \mathrm{~d}$ in situ with dynamic loading. Data were normalised to expression level of PUCol-AFCs. $n=4,{ }^{*} p<0.1,{ }^{* *} p<0.01$ vs. gene expression levels of PU-Col-AFCs. vivo organ culture study, addition of TGF- $\beta 1$ within the hydrogel induced COL1A1 expression of human AF cells (Fig. 7), highlighting the context-specific behaviours of TGF- $\beta 1$. These results indicated that the native AF tissue microenvironment in situ may orient the effect of TGF- $\beta 1$ towards the native cell phenotype. ELN expression was also upregulated in implanted AF cells by TGF- $\beta 1$ supplementation (Fig. 7 ), which plays an important role in maintenance of collagen organisation and recovery of the disc size and shape after deformation (Yu et al., 2002). Nakai et al. (2016) showed that ELN upregulation in CD146 ${ }^{+}$AF cells may contribute to the development of a contractile phenotype in these AF cells. SCX, a basic helix-loop-helix transcription factor that marks the tendon/ligament cell lineage and is present in the AF (Pryce et al., 2007; Yoshimoto et al., 2017), was highly upregulated in both 2D and 3D cultures treated with TGF- $\beta 1$ (Fig. 2a, 4). Interestingly, it had lower expression in oAF vs. NP in bovine IVD (Fig. 1). However, $S C X^{+} A F$ cells function in healing of AF rupture in neonatal mice (Torre et al., 2018), which may explain the low expression level in mature bovine AF tissue. IVD cells fail to maintain the balance of anabolism and catabolism during ageing and degeneration, with decreased ECM synthesis and increased ECM degrading enzymes, such as MMP and ADAMTS family. The upregulation of MMP3 and ADAMTS5 has been reported in degenerated IVDs (Vo et al., 2013). Present results showed that TGF- $\beta 1$ not only upregulated ECM production but also downregulated the expression of ECM catabolic enzymes MMP3 and ADAMTS5 (Fig. 2a, 4). This indicated that TGF- $\beta 1$-treated AF cells may possess an anti-catabolic effect in AF rupture repair for prevention of further tissue degeneration. When AF cells were cultured in collagen I hydrogel both in vitro and ex vivo, higher cell density was found in TGF- $\beta 1$ supplemented scaffolds (Fig. 3,6), which indicated that TGF- $\beta 1$ promoted cell proliferation and/or cell survival of human AF cells. This is essential for rebuilding of the biological function when cells are implanted into the avascular disc milieu. In summary, results showed that TGF- $\beta 1$ was an effective agent for biological functional recovery of AF.

PU materials are promising biomaterials for AF regeneration, as they are biodegradable, biocompatible, mechanically robust and elastic (Agnol et al., 2018; Yeganegi et al., 2010). In the present study, AF cells were evenly distributed within the porous PU scaffold, with or without collagen gel as a cell carrier (Fig. 3a-c). Furthermore, the scaffold size can be easily tuned for custom-designed patient need in further application. Type I collagen is a component of AF matrix and was used to deliver the functional AF cells in PU scaffold and create a biomimetic environment of AF. Collagen type I has been reported to promote AF cells proliferation and matrix production in vitro (Xiao et al., 2017). Present results showed that collagen I hydrogel maintained AF cell survival after $7 \mathrm{~d}$ of $3 \mathrm{D}$ culture in vitro but did not further enhance cell proliferation. Importantly, collagen I hydrogel as a cell carrier could preserve the functional phenotype of TGF- $\beta 1$-induced human AF cells, as indicated by higher expression level of CD146, SM22 $\alpha$ and MKX as compared with PU scaffold only (Fig. 4). These results demonstrated the potential capacity of collagen I hydrogel for cell delivery and functional phenotype maintenance in AF rupture repair.

In the ex vivo preclinical study, AF defects were repaired with PU-Col constructs and PU membrane sealing. After $14 \mathrm{~d}$ of organ culture under daily dynamic loading, PU-Col constructs could still completely fill the AF defect and no herniation of NP tissue was found. While in injury control discs, part of the NP tissue protruded into the AF defect area (Fig. 6). Implantation of AF cells into the AF 
defect was carried out by delivering them in PU-Col constructs. After $14 \mathrm{~d}$ of in situ culture with daily dynamic load, the implanted AF cells remained in the PU-Col constructs and started matrix production. Interestingly, cell density and matrix production were more pronounced when TGF- $\beta 1$ had been added in the constructs. On the other hand, cells expressed significantly higher COL1A1 and showed a trend for higher levels of CD146 and ELN in TGF- 31 -supplied constructs. These results indicated that TGF- $\beta 1$ administration within the selected biomaterial could better facilitate the enhancement of functional AF cell phenotype and neo-tissue formation in situ. Pirvu et al. (2015) showed that implantation of MSCs positively modulates cell phenotype of host disc tissue by up-regulating anabolic mechanisms and down-regulating catabolic mechanisms by paracrine effect. However, there was no evidence showing the same effect on native disc tissue with AF cells implantation (Fig. 8); while new matrix production was only observed with the functional AF cells implantation. These findings suggested that MSCs and AF cells had different mechanisms of action. MSCs, which can be derived from a wide range of sources, can positively modulate cells of the host disc tissue, but may have limited potential for AF matrix production. In contrast, AF cells are suitable for neo-tissue formation, but do not influence the phenotype of adjacent host cells. To further improve the homeostasis in AF tissue repair and prevent further IVD degeneration, combination of functional AF cells and the effective paracrine factors from MSCs may bring further valued outcomes.

The limitations of the current study remain in the following aspects: the random porous architecture of the PU scaffold likely did not promote matrix deposition in an angle-plied lamellar microstructure similar to that of native AF fibres, despite its good cell seeding capacity. Implementation of additive manufacturing for production of PU scaffolds may further promote maintenance/induction of the functional AF cell phenotype and formation of a native-mimicking ECM structure. Both in vitro and ex vivo studies were performed with 2 weeks followup. Further longer follow-up study may be needed to evaluate long-term culture properties such as cell survival, ECM production and degradation of PU scaffold. Additional studies with high force, fatigue and complex loading to evaluate herniation risk of the construct are needed. Ultimately, in vivo, a higher load is expected in the disc. A press-fit and biocompatible material filler is needed to close the defect and restore the mechanical function of the IVD with high adhesion strength and adequate compressive, shear and tensile moduli (Long et al., 2016), to provide structural support for the biological repair.
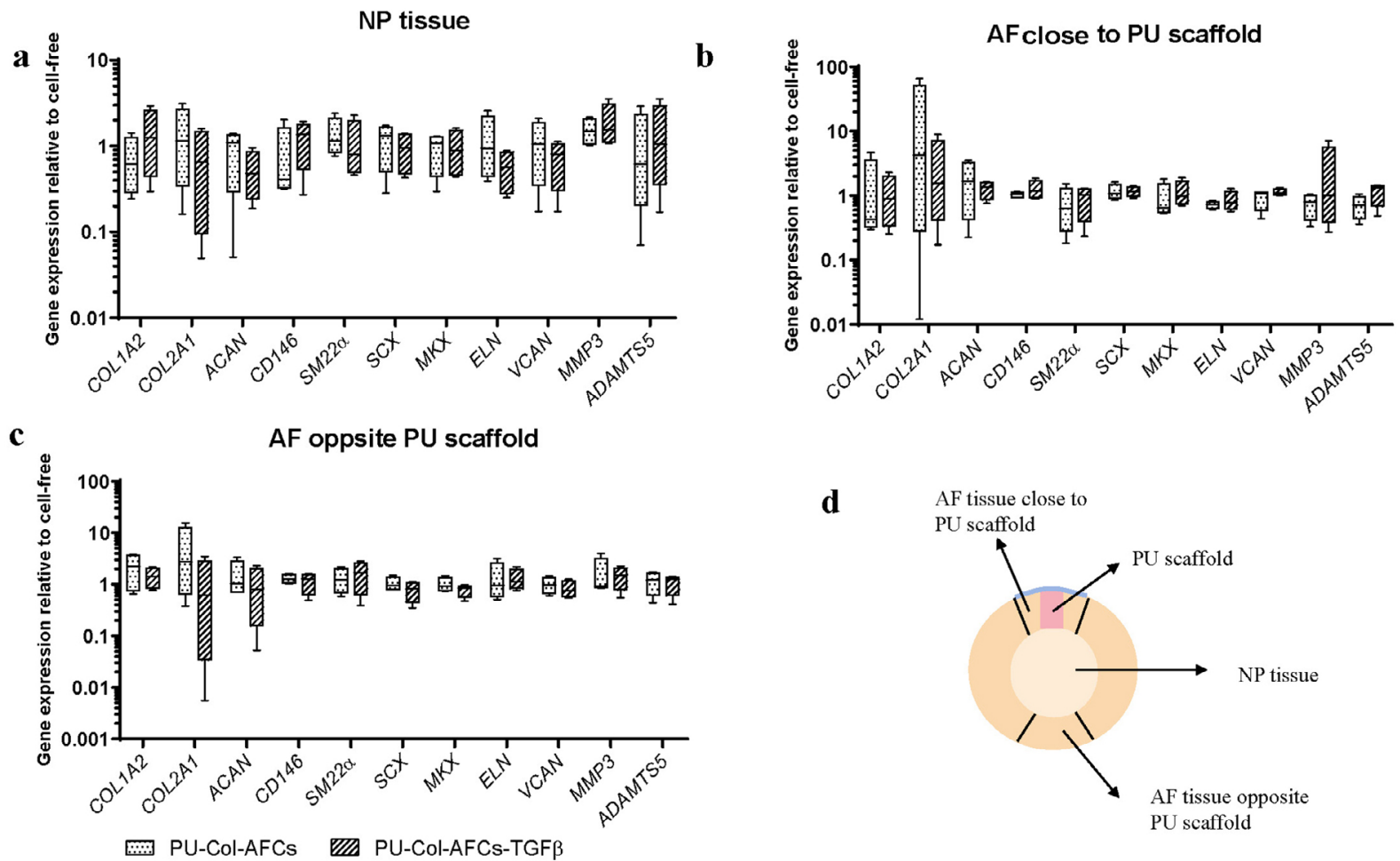

Fig. 8. Relative mRNA expression of host disc tissue after $15 \mathrm{~d}$ of organ culture. Relative mRNA expression in (a) NP, (b) adjacent AF and (c) distal AF tissue of discs repaired with PU-Col cell-free (PU-Col), PU-Col scaffold seeded with TGF- 31 -pre-treated AF cells (PU-Col-AFCs) and PU-Col-AFCs supplemented with TGF- $\beta 1$ (PU-Col-AFCs-TGF $\beta$ ) after $15 \mathrm{~d}$ of organ culture with dynamic loading. Data were normalised to the expression level of PU-Col. $n=4$. (d) Transverse schematic view of discs implanted with scaffolds and disc tissue collected for gene expression analysis. 


\section{Conclusions}

The current study explored a novel AF repair strategy aiming at functional cell phenotype induction. A set of AF cell phenotype markers were defined in healthy AF tissue as compared with NP, including COL1A2, CD146, SM22 $\alpha$ and MKX. TGF- $\beta 1$ upregulated gene and protein expression of the AF cell markers in human mildly degenerated AF cells and increased cell contractility, indicating that TGF- $\beta 1$-pre-treated AF cells may be an appropriate cell source for AF tissue engineering or rupture repair. Collagen type I hydrogel as a cell carrier in the PU scaffold maintained the phenotype of human AF cells. TGF- $\beta 1$ treatment within the collagen hydrogel further promoted cell proliferation and matrix production of AF cells both in vitro and ex vivo. TGF- $\beta 1$ and collagen type I hydrogel-PU scaffold hybrid system retained the AF phenotype of implanted cells. These constructs have potential for generating tissue engineered AF and warrant further investigation for their use in repairing AF defects after discectomy.

\section{Acknowledgements}

The study was supported by the AO Foundation, AO Spine International, National Natural Science Foundation of China (81772333, 51873069) and National Institutes of Health (R01AR064157). Jie Du was supported by the European Union's Horizon 2020 research and innovation programme under Marie Sklodowska-Curie fellowship (642414). Rose Long was supported by the Whitaker Foundation.

\section{References}

Agnol LD, Gonzalez Dias FT, Nicoletti NF, Falavigna A, Bianchi O (2018) Polyurethane as a strategy for annulus fibrosus repair and regeneration: a systematic review. Regen Med 13: 611-626.

Ahlgren BD, Lui W, Herkowitz HN, Panjabi MM, Guiboux JP (2000) Effect of anular repair on the healing strength of the intervertebral disc: a sheep model. Spine (Phila Pa 1976) 25: 2165-2170.

Alini M, Li W, Markovic P, Aebi M, Spiro RC, Roughley PJ (2003) The potential and limitations of a cell-seeded collagen/hyaluronan scaffold to engineer an intervertebral disc-like matrix. Spine (Phila Pa 1976) 28: 446-454.

Ambrossi GL, McGirt MJ, Sciubba DM, Witham TF, Wolinsky JP, Gokaslan ZL, Long DM (2009) Recurrent lumbar disc herniation after single-level lumbar discectomy: incidence and health care cost analysis. Neurosurgery 65: 574-578.

Bailey A, Araghi A, Blumenthal S, Huffmon GV, Anular Repair Clinical Study Group (2013) Prospective, multicenter, randomized, controlled study of anular repair in lumbar discectomy: twoyear follow-up. Spine (Phila Pa 1976) 38: 1161-1169.
Blanquer SBG, Gebraad AWH, Miettinen S, Poot AA, Grijpma DW, Haimi SP (2017) Differentiation of adipose stem cells seeded towards annulus fibrosus cells on a designed poly(trimethylene carbonate) scaffold prepared by stereolithography. J Tissue Eng Regen Med 11: 2752-2762.

Boissard CI, Bourban PE, Tami AE, Alini M, Eglin D (2009) Nanohydroxyapatite/poly(ester urethane) scaffold for bone tissue engineering. Acta Biomater 5: 3316-3327.

Borem R, Madeline A, Walters J, Mayo H, Gill S, Mercuri J (2017) Angle-ply biomaterial scaffold for annulus fibrosus repair replicates native tissue mechanical properties, restores spinal kinematics, and supports cell viability. Acta Biomater 58: 254-268.

Bowles RD, Williams RM, Zipfel WR, Bonassar LJ (2010) Self-assembly of aligned tissue-engineered annulus fibrosus and intervertebral disc composite via collagen gel contraction. Tissue Eng Part A 16: 1339-1348.

Bron JL, Helder MN, Meisel HJ, Van Royen BJ, Smit TH (2009) Repair, regenerative and supportive therapies of the annulus fibrosus: achievements and challenges. Eur Spine J 18: 301-313.

Caprez SMU, Li Z, Grad S, Alini M, Peroglio M (2018) Isolation of high-quality RNA from intervertebral disc tissue via pronase pre-digestion and tissue pulverization. JOR Spine 1: e1017. DOI: 10.1002/jsp2.1017.

Carragee EJ, Han MY, Suen PW, Kim D (2003) Clinical outcomes after lumbar discectomy for sciatica: the effects of fragment type and anular competence. J Bone Joint Surg Am 85-A: 102-108.

Chou PH, Wang ST, Ma HL, Liu CL, Chang MC, Lee OK (2016) Development of a two-step protocol for culture expansion of human annulus fibrosus cells with TGF- $\beta 1$ and FGF-2. Stem Cell Res Ther 7: 89. DOI: 10.1186/s13287-016-0332-1.

Chu G, Shi C, Lin J, Wang S, Wang H, Liu T, Yang H, Li B (2018) Biomechanics in annulus fibrosus degeneration and regeneration. Adv Exp Med Biol 1078: 409-420.

Costi JJ, Stokes IA, Gardner-Morse M, Laible JP, Scoffone HM, Iatridis JC (2007) Direct measurement of intervertebral disc maximum shear strain in six degrees of freedom: motions that place disc tissue at risk of injury. J Biomech 40: 2457-2466.

Dionne CE, Dunn KM, Croft PR (2006) Does back pain prevalence really decrease with increasing age? A systematic review. Age Ageing 35: 229-234.

Frauchiger DA, May RD, Bakirci E, Tekari A, Chan SCW, Woltje M, Benneker LM, Gantenbein B (2018) Genipin-enhanced fibrin hydrogel and novel silk for intervertebral disc repair in a loaded bovine organ culture model. J Funct Biomater 9: E40. DOI: 10.3390/ jfb9030040.

Freeman BJ, Kuliwaba JS, Jones CF, Shu CC, Colloca CJ, Zarrinkalam MR, Mulaibrahimovic A, Gronthos S, Zannettino AC, Howell S (2016) Allogeneic mesenchymal precursor cells promote healing in postero-lateral annular lesions and improve 
indices of lumbar intervertebral disc degeneration in an ovine model. Spine (Phila Pa 1976) 41: 1331-1339.

Gorna K, Gogolewski S (2006) Biodegradable porous polyurethane scaffolds for tissue repair and regeneration. J Biomed Mater Res A 79: 128-138.

Goupille P, Jayson MI, Valat JP, Freemont AJ (1998) The role of inflammation in disk herniationassociated radiculopathy. Semin Arthritis Rheum 28: 60-71.

Grad S, Kupcsik L, Gorna K, Gogolewski S, Alini M (2003) The use of biodegradable polyurethane scaffolds for cartilage tissue engineering: potential and limitations. Biomaterials 24: 5163-5171.

Gruber HE, Leslie K, Ingram J, Hoelscher G, Norton HJ, Hanley EN, Jr. (2004) Colony formation and matrix production by human anulus cells: modulation in three-dimensional culture. Spine (Phila Pa 1976) 29: E267-274.

Guterl CC, Torre OM, Purmessur D, Dave K, Likhitpanichkul M, Hecht AC, Nicoll SB, Iatridis JC (2014) Characterization of mechanics and cytocompatibility of fibrin-genipin annulus fibrosus sealant with the addition of cell adhesion molecules. Tissue Eng Part A 20: 2536-2545.

Hayes AJ, Ralphs JR (2011) The response of foetal annulus fibrosus cells to growth factors: modulation of matrix synthesis by TGF- $\beta 1$ and IGF- 1 . Histochem Cell Biol 136: 163-175.

Heuer F, Ulrich S, Claes L, Wilke HJ (2008) Biomechanical evaluation of conventional anulus fibrosus closure methods required for nucleus replacement. Laboratory investigation. J Neurosurg Spine 9: 307-313.

Hoy D, Bain C, Williams G, March L, Brooks P, Blyth F, Woolf A, Vos T, Buchbinder R (2012) A systematic review of the global prevalence of low back pain. Arthritis Rheum 64: 2028-2037.

Hoy D, March L, Brooks P, Woolf A, Blyth F, Vos T, Buchbinder R (2010) Measuring the global burden of low back pain. Best Pract Res Clin Rheumatol 24: 155-165.

Humphreys SC, Eck JC (1999) Clinical evaluation and treatment options for herniated lumbar disc. Am Fam Physician 59: 575-582.

Hussain I, Sloan SR, Wipplinger C, NavarroRamirez R, Zubkov M, Kim E, Kirnaz S, Bonassar LJ, Hartl R (2018) Mesenchymal stem cell-seeded high-density collagen gel for annular repair: 6-week results from in vivo sheep models. Neurosurgery 85: E350-E359.

Iatridis JC, Nicoll SB, Michalek AJ, Walter BA, Gupta MS (2013) Role of biomechanics in intervertebral disc degeneration and regenerative therapies: what needs repairing in the disc and what are promising biomaterials for its repair? Spine J 13: 243-262.

Iu J, Massicotte E, Li SQ, Hurtig MB, Toyserkani E, Santerre JP, Kandel RA (2017) In vitro generated intervertebral discs: toward engineering tissue integration. Tissue Eng Part A 23: 1001-1010.
Lang G, Liu Y, Geries J, Zhou Z, Kubosch D, Sudkamp N, Richards RG, Alini M, Grad S, Li Z (2018) An intervertebral disc whole organ culture system to investigate proinflammatory and degenerative disc disease condition. J Tissue Eng Regen Med 12: e2051-e2061.

Lee CR, Grad S, Gorna K, Gogolewski S, Goessl A, Alini M (2005) Fibrin-polyurethane composites for articular cartilage tissue engineering: a preliminary analysis. Tissue Eng 11: 1562-1573.

Li Z, Kupcsik L, Yao SJ, Alini M, Stoddart MJ (2009) Chondrogenesis of human bone marrow mesenchymal stem cells in fibrin-polyurethane composites. Tissue Eng Part A 15: 1729-1737.

Long RG, Torre OM, Hom WW, Assael DJ, Iatridis JC (2016) Design requirements for annulus fibrosus repair: review of forces, displacements, and material properties of the intervertebral disk and a summary of candidate hydrogels for repair. J Biomech Eng 138: 0210071-02100714.

Molinos M, Almeida CR, Goncalves RM, Barbosa MA (2015) Improvement of bovine nucleus pulposus cells isolation leads to identification of three phenotypically distinct cell subpopulations. Tissue Eng Part A 21: 2216-2227.

Nakai T, Sakai D, Nakamura Y, Nukaga T, Grad S, Li Z, Alini M, Chan D, Masuda K, Ando K, Mochida J, Watanabe M (2016) CD146 defines commitment of cultured annulus fibrosus cells to express a contractile phenotype. J Orthop Res 34: 1361-1372.

Nakamichi R, Ito Y, Inui M, Onizuka N, Kayama T, Kataoka K, Suzuki H, Mori M, Inagawa M, Ichinose S, Lotz MK, Sakai D, Masuda K, Ozaki T, Asahara H (2016) Mohawk promotes the maintenance and regeneration of the outer annulus fibrosus of intervertebral discs. Nat Commun 7: 12503. DOI: 10.1038/ncomms12503.

Pattappa G, Li Z, Peroglio M, Wismer N, Alini M, Grad S (2012) Diversity of intervertebral disc cells: phenotype and function. J Anat 221: 480-496.

Pirvu T, Blanquer SB, Benneker LM, Grijpma DW, Richards RG, Alini M, Eglin D, Grad S, Li Z (2015) A combined biomaterial and cellular approach for annulus fibrosus rupture repair. Biomaterials 42: 11-19.

Pryce BA, Brent AE, Murchison ND, Tabin CJ, Schweitzer R (2007) Generation of transgenic tendon reporters, ScxGFP and ScxAP, using regulatory elements of the scleraxis gene. Dev Dyn 236: 16771682.

Roberts S, Evans H, Trivedi J, Menage J (2006) Histology and pathology of the human intervertebral disc. J Bone Joint Surg Am 88 Suppl 2: 10-14.

Sakai D, Grad S (2015) Advancing the cellular and molecular therapy for intervertebral disc disease. Adv Drug Deliv Rev 84: 159-171.

Sakai D, Nakamura Y, Nakai T, Mishima T, Kato S, Grad S, Alini M, Risbud MV, Chan D, Cheah KS, Yamamura K, Masuda K, Okano H, Ando K, Mochida J (2012) Exhaustion of nucleus pulposus 
progenitor cells with ageing and degeneration of the intervertebral disc. Nat Commun 3: 1264. DOI: 10.1038/ncomms2226.

Schmidt H, Kettler A, Heuer F, Simon U, Claes L, Wilke HJ (2007) Intradiscal pressure, shear strain, and fiber strain in the intervertebral disc under combined loading. Spine (Phila Pa 1976) 32: 748-755.

Sloan SR, Jr., Lintz M, Hussain I, Hartl R, Bonassar LJ (2018) Biologic annulus fibrosus repair: a review of preclinical in vivo investigations. Tissue Eng Part B Rev 24: 179-190.

Smith JS, Ogden AT, Shafizadeh S, Fessler RG (2010) Clinical outcomes after microendoscopic discectomy for recurrent lumbar disc herniation. J Spinal Disord Tech 23: 30-34.

Tomasek JJ, Gabbiani G, Hinz B, Chaponnier C, Brown RA (2002) Myofibroblasts and mechanoregulation of connective tissue remodelling. Nat Rev Mol Cell Biol 3: 349-363.

Torre OM, Das R, Berenblum RE, Huang AH, Iatridis JC (2018) Neonatal mouse intervertebral discs heal with restored function following herniation injury. FASEB J 32: 4753-4762.

Torre OM, Mroz V, Bartelstein MK, Huang AH, Iatridis JC (2019) Annulus fibrosus cell phenotypes in homeostasis and injury: implications for regenerative strategies. Ann N Y Acad Sci 1442: 61-78.

Vo NV, Hartman RA, Yurube T, Jacobs LJ, Sowa GA, Kang JD (2013) Expression and regulation of metalloproteinases and their inhibitors in intervertebral disc aging and degeneration. Spine J 13: 331-341.

Wang Y, Wang X, Shang J, Liu H, Yuan Y, Guo Y, Huang B, Zhou Y (2017) Repairing the ruptured annular fibrosus by using type I collagen combined with citric acid, EDC and NHS: an in vivo study. Eur Spine J 26: 884-893.

Watters WC, 3rd, McGirt MJ (2009) An evidencebased review of the literature on the consequences of conservative versus aggressive discectomy for the treatment of primary disc herniation with radiculopathy. Spine J 9: 240-257.

Whatley BR, KuoJ, Shuai C, Damon BJ, Wen X(2011) Fabrication of a biomimetic elastic intervertebral disk scaffold using additive manufacturing. Biofabrication 3: 015004. DOI: 10.1088/1758-5082/3/1/015004.

Xiao L, Ding M, Saadoon O, Vess E, Fernandez A, Zhao P, Jin L, Li X (2017) A novel culture platform for fast proliferation of human annulus fibrosus cells. Cell Tissue Res 367: 339-350.

Yang L, Kandel RA, Chang G, Santerre JP (2009) Polar surface chemistry of nanofibrous polyurethane scaffold affects annulus fibrosus cell attachment and early matrix accumulation. J Biomed Mater Res A 91: 1089-1099.

Yeganegi M, Kandel RA, Santerre JP (2010) Characterization of a biodegradable electrospun polyurethane nanofiber scaffold: mechanical properties and cytotoxicity. Acta Biomater 6: 38473855.
Yoshimoto Y, Takimoto A, Watanabe H, Hiraki Y, Kondoh G, Shukunami C (2017) Scleraxis is required for maturation of tissue domains for proper integration of the musculoskeletal system. Sci Rep 7: 45010. DOI: 10.1038/srep45010.

Yu J, Winlove PC, Roberts S, Urban JP (2002) Elastic fibre organization in the intervertebral discs of the bovine tail. J Anat 201: 465-475.

Zhang J, Li Z, Chen F, Liu H, Wang H, Li X, Liu X, Wang J, Zheng Z (2017) TGF- $\beta 1$ suppresses CCL3/4 expression through the ERK signaling pathway and inhibits intervertebral disc degeneration and inflammation-related pain in a rat model. Exp Mol Med 49: e379. DOI: 10.1038/emm.2017.136.

\section{Discussion with Reviewers}

Cornelia Neidlinger-Wilke: Does the organ culture model really simulate in vivo loading conditions? The risk of herniation is certainly lower under the applied experimental conditions. Could you please comment on this?

Authors: In the current study, the IVD organs were cultured under physiological axial compressive loading condition. This model partially simulated the in vivo loading conditions by resulting in a disc height loss of $\sim 10 \%$ after loading, which is comparable to the disc height loss of human lumbar IVD after normal daily activity. However, this model does not simulate the complex in vivo loading condition, including flexion, extension and torsion. In this respect, the risk of herniation is certainly lower under the applied experimental conditions. Further mechanical test under complex loading condition is needed to assess the biomechanical compatibility of the implanted constructs and fixation method. The current model simulated the biological microenvironment of in vivo native disc tissue for testing of the implanted constructs, representing a good pre-animal model to evaluate the biological compatibility of the implanted constructs in addition to an in vitro system.

Cornelia Neidlinger-Wilke: Regarding a possible in vivo application of such an approach, is this also an appropriate solution under the high loaded conditions in the physiological disc environment? Does the PU membrane sealing also persist under complex loading conditions? How can the risk of extrusion under high and complex load exposure be reduced?

Authors: We agree with the reviewer that many more challenges remain to be solved regarding the application of this method for AF repair in vivo. In the current study, EPIGLU ${ }^{\circledR}$ (Meyer-Haake $\mathrm{GmbH}$ ) was used to stick a membrane for maintaining the scaffold in place under a loaded environment. In a previous study, a membrane-suture method was used to fix the implant (Pirvu et al., 2015). These could all be possible options for scaffold fixation. For easier 
operation-room practice, the cell-seeded scaffold could be further developed into an adhesive patch to avoid manipulation hassles.

Fackson Mwale: In the NP, TGF- $\beta 1$ downregulates CCL4 expression through ERK1/2 signalling activation (Zhang et al., 2017, additional reference). What are the mechanisms underlying the effects of TGF- $\beta 1$ on AF phenotypic induction?

Authors: According to Zhang et al. (2017), TGF- $\beta 1$ can prevent degenerative processes, inhibit inflammatory responses in the dorsal root ganglia and prevent pain development, by inhibiting CCL4 expression via ERK1/2 signalling activation in NP cells. However, the mechanism of TGF- $\beta 1$ on functional AF phenotypic induction is yet unclear. Preliminary results showed that ERK1/2 inhibitor promoted AF functional marker expression independent of TGF- $\beta 1$ treatment, which indicated that ERK1/2 signalling pathway might also play a role in the regulation of AF phenotype markers expression. Ongoing study suggests that Smads pathway may play a key role in the effects of TGF- $\beta 1$ on AF phenotypic induction. Further experiments are needed to confirm these preliminary findings.

Fackson Mwale: Would intradiscal injections of TGF- $\beta 1$ and AF cells be effective?

Authors: Intradiscal injection of TGF- $\beta 1$ and AF cells may be effective for repair of small AF ruptures. In case of a large AF defect, an adhesive and biocompatible material filler to close the defect and restore the mechanical function of the IVD will be needed to provide structural support for the biological repair.

Fackson Mwale: One of the limitations of the study, as pointed out, was the lack of the angle-ply, fibrillar organisation of the native AF. Would a 3D-printed scaffold in which the layers are printed in opposing angular orientations replicating the angle-ply arrangement of the native tissue be suitable for the collagen PU scaffold used?

Authors: It is a great suggestion to use a 3D-printed scaffold to mimic the angle-plied lamellae structure of the native AF tissue. Christiani et al. (2019, additional reference) developed a tissue engineered AF by 3D-printed polycaprolactone scaffolds with angle- plied architecture. It would be also suitable with collagen and PU, since both collagen I and PU have been widely used for 3D bioprinting. One potential direction is to print PU with an angle-plied structure as a backbone platform to supply the mechanical property and to print another layer of collagen I encapsulated with functional cells and bioactive agents within the space between the PU layers.

Fackson Mwale: How does this scaffold compare with the tensile, compressive and torsional mechanics of the AF?

Authors: The unconfined compressive stiffness of porous PU scaffold is approximately $20 \mathrm{kPa}$, which is weaker than the native AF tissue (0.19-0.26 MPa) (Freeman et al., 2013, additional reference). The tensile and torsional mechanical properties of the PU scaffold were not measured in the current study. Further testing is needed to fully understand the mechanical property of the scaffold. The mechanical properties of the scaffold may be improved by mimicking the angle-plied lamellar microstructure of AF instead of random porous architecture. This may be achieved by using other technologies, such as electrospinning and 3D printing in further studies.

\section{Additional References}

Christiani TR, Baroncini E, Stanzione J, Vernengo AJ (2019) In vitro evaluation of 3D printed polycaprolactone scaffolds with angle-ply architecture for annulus fibrosus tissue engineering. Regen Biomater 6: 175-184.

Freeman AL, Buttermann GR, Beaubien BP, Rochefort WE (2013) Compressive properties of fibrous repair tissue compared to nucleus and annulus. J Biomech 46: 1714-1721.

Zhang J, Li Z, Chen F, Liu H, Wang H, Li X, Liu X, Wang J, Zheng Z (2017) TGF- $\beta 1$ suppresses CCL3/4 expression through the ERK signaling pathway and inhibits intervertebral disc degeneration and inflammation-related pain in a rat model. Exp Mol Med 49: e379. DOI: 10.1038/emm.2017.136.

Editor's note: The Scientific Editor responsible for this paper was Brian Johnstone. 